\title{
Atmospheric oxygen and carbon dioxide observations from two European coastal stations 2000-2005: continental influence, trend changes and APO climatology
}

\author{
C. Sirignano ${ }^{1}$, R. E. M. Neubert ${ }^{1}$, C. Rödenbeck ${ }^{2}$, and H. A. J. Meijer ${ }^{1}$ \\ ${ }^{1}$ Centre for Isotope Research, University of Groningen, Nijenborgh 4, 9747 AG Groningen, The Netherlands \\ ${ }^{2}$ Max-Planck-Institute for Biogeochemistry, Hans-Knoell-Straße 10, 07745 Jena, Germany
}

Received: 20 August 2008 - Published in Atmos. Chem. Phys. Discuss.: 28 November 2008

Revised: 26 January 2010 - Accepted: 29 January 2010 - Published: 15 February 2010

\begin{abstract}
Seeking for baseline conditions has biased the atmospheric carbon dioxide $\left(\mathrm{CO}_{2}\right)$ and later on also oxygen $\left(\mathrm{O}_{2}\right)$ monitoring networks towards remote marine stations, missing part of the variability that is due to regional anthropogenic as well as land biotic activity. We present here a five-year record of atmospheric $\mathrm{CO}_{2}$ concentrations and oxygen/nitrogen $\left(\mathrm{O}_{2} / \mathrm{N}_{2}\right)$ ratio measurements from the coastal stations Lutjewad (LUT), The Netherlands and Mace Head (MHD), Ireland, derived from flask samples. $\mathrm{O}_{2} / \mathrm{N}_{2}$ ratios, a proxy for $\mathrm{O}_{2}$ concentrations, concurrently measured with $\mathrm{CO}_{2}$ concentrations, help determine regional $\mathrm{CO}_{2}$ fluxes by separating land fluxes from sea fluxes. Mace Head is the closest marine baseline station to Lutjewad, located at the same latitude, and therefore is taken as a reference. During the studied period, from 2000 until 2005, we observed an average increase of $\mathrm{CO}_{2}$ in the atmosphere of (1.7 \pm 0.2$) \mathrm{ppm} \mathrm{y}^{-1}$, and a change of the $\mathrm{O}_{2} / \mathrm{N}_{2}$ ratio of $(-20 \pm 1)$ per meg $y^{-1}$. The difference between the $\mathrm{CO}_{2}$ summer minimum and the winter maximum is $14.4 \mathrm{ppm}$ and $16.1 \mathrm{ppm}$ at Mace Head and Lutjewad, respectively, while the paraphase variation in the $\mathrm{O}_{2}$ signal equals 113 per meg and 153 per meg, respectively. We also studied the atmospheric potential oxygen (APO) tracer at both stations. By this analysis, evidence has been found that we need to be careful when using APO close to anthropogenic $\mathrm{CO}_{2}$ sources. It could be biased by combustion-derived $\mathrm{CO}_{2}$, and models need to take into account daily and seasonal variations in the anthropogenic $\mathrm{CO}_{2}$ production in order to be able to simulate APO over the continents.
\end{abstract}

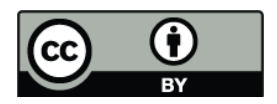

Correspondence to: R. E. M. Neubert (r.e.m.neubert@rug.nl)

\section{Introduction}

High-precision measurements of atmospheric $\mathrm{O}_{2}$ concentrations have delivered important constraints for our understanding of the global carbon budget during the last almost twenty years (e.g. Keeling et al., 1993; Manning and Keeling, 2006). This is possible as the global $\mathrm{O}_{2}$ cycle is closely coupled to the global carbon cycle, with their concentration changes being anticorrelated for all but one major exchange mechanism: there is no mirroring $\mathrm{O}_{2}$-flux from the ocean to the atmosphere connected to the long-term uptake of $\mathrm{CO}_{2}$ into the ocean by increased atmospheric $\mathrm{CO}_{2}$ concentrations. This feature enables us to find an answer to the still open question: which fraction of the $\mathrm{CO}_{2}$ produced by human activities is transferred into either of the two other reservoirs involved, the land biosphere or the world oceans. Building on this knowledge, we would like to know which processes are responsible for this partitioning, how large the interannual variability or eventual trends are, and if a forecast of future $\mathrm{CO}_{2}$ partitioning might be possible. From international fossil fuel trade and landuse-change statistics on one side and atmospheric observations on the other side we know that only roughly half of the anthropogenic $\mathrm{CO}_{2}$ stays in the atmosphere (IPCC, 2007). Both other reservoirs have strongly differing mean turnover times for $\mathrm{CO}_{2}$, thus storing $\mathrm{CO}_{2}$ for different periods of time before we have to account for its reentrance into the atmosphere. That is why this partition ratio is required for climate projections. The knowledge about the effects and pathways of the anthropogenic perturbation of the natural carbon cycle is essential information in order to design effective policies and mitigation options aimed at minimizing anthropogenically induced climate change.

Published by Copernicus Publications on behalf of the European Geosciences Union. 
Through measurements of the decadal trends in both the atmospheric $\mathrm{O}_{2}$ and $\mathrm{CO}_{2}$ concentrations we can reconstruct the global budget of the two species (Keeling et al., 1993, 1996; Bender et al., 1996; Keeling and Shertz, 1992; Battle et al., 2000). They also serve as constraints in multitracer inverse model simulations to study the spatiotemporal variability of those $\mathrm{CO}_{2}$ sources and sinks (Le Quéré et al., 2003; Rayner et al., 1999; Bender et al., 1996). Apart from the trend, the seasonal variations of atmospheric $\mathrm{O}_{2}$, can be applied to learn about the primary production in the oceans (Keeling and Shertz, 1992; Balkanski et al., 1999; Bender et al., 1996) or in general about seasonal patterns of oceanic processes causing fluxes at the air-sea interface and inter-hemispheric gradients (Keeling et al., 1998; Stephens et al., 1998; Battle et al., 2006; Garcia and Keeling, 2001).

$\mathrm{CO}_{2}$ and $\mathrm{O}_{2}$ have strongly differing seawater solubility, and, contrary to $\mathrm{O}_{2}, \mathrm{CO}_{2}$ is involved in the oceanic carbonate-buffer system. Thus only a small portion of carbon within the Global Carbon Cycle of atmosphere, biosphere and oceans is air-borne, but the majority of carbon is solved in the oceans. Also seasonal changes in the oceanic $\mathrm{CO}_{2}$ content are largely buffered and, thus, not transferred into the atmosphere. The ocean biosphere does not put a remarkable imprint on the atmospheric carbon cycle when compared to the land biota. For $\mathrm{O}_{2}$ the situation is just reversed. As $\mathrm{O}_{2}$ has a low solubility in water, seasonal variations in the seawater $\mathrm{O}_{2}$ content derived from photosynthetic activity and decomposition are quickly transferred to the atmosphere, with a diffusion-controlled time-lag of 22 days (Keeling et al., 1993). This way the ocean biosphere is responsible for the largest part of the seasonal $\mathrm{O}_{2}$ concentration changes in the southern hemispheric atmosphere, the seasonal amplitude being very similar to that of the northern hemisphere where the land biosphere contributes much more to the total. According to the general climatic conditions (dependent on insolation), there is a strong north-south gradient (low in the tropics, high towards the poles) in the amplitude of the seasonal cycle in the fluxes.

In order to quantify the coupling between the global $\mathrm{O}_{2}$ and carbon cycles, the oxidative ratio (OR) is defined as the ratio of moles $\mathrm{O}_{2}$ and $\mathrm{CO}_{2}$, concurrently exchanged in a given process, counted in the same transport direction, thus rendering a positive number, i.e. $\mathrm{OR}=\Delta \mathrm{mol} \mathrm{O}_{2}: \Delta \mathrm{mol} \mathrm{CO}_{2}$. Plants, when photosynthetically producing $\mathrm{O}_{2}$, take up $\mathrm{CO}_{2}$ from the atmosphere in a certain OR slightly larger than unity. The deviation from unity is due to the incorporation of elements other than carbon, that also need to be reduced from oxidized compounds. As plants produce material with different function and elemental ratios during their annual and life cycles, the actual OR thus may vary. Land-use changes may even lead to changes in the global mean OR (Randerson et al., 2006). The built-up organic material will once be oxidized again, a process taking up $\mathrm{O}_{2}$ and releasing $\mathrm{CO}_{2}$ (and other oxidized elements). Fossil fuel combustion is using up $\mathrm{O}_{2}$ for $\mathrm{CO}_{2}$ production with an $\mathrm{OR}$ that also depends on the content of other oxidable elements apart from carbon. For liquid and gaseous hydrocarbons, this is mainly determined by their hydrogen content. As for the possible extreme values we note that the oxidative ratio of pure carbon is 1 , while the oxidative ratio of methane is 2 , as with every molecule of $\mathrm{CO}_{2}$ two molecules of water are formed. The generally used oxidative ratios are 1.95 for natural gas, 1.44 for liquid fuels and 1.17 for coal (Keeling, 1988).

The fossil fuel mix of a country or region is mainly known from annual sales statistics, which until now introduces an unrealistic constancy in simulations, as compared to the actual combustion processes due to varying energy needs. Efforts are being made in order to describe and simulate the actual time-resolved and space-resolved fuel usage by defining major stationary as well as mobile users and their respective fuel consumption over time in weekly and annual cycles, on scales of kilometres and hours (Olivier and Berdowski, 2001, and new developments in EDGAR (Emission Database for Global Atmospheric Research), cf. www.mnp.nl/edgar). The energy demand of The Netherlands, where LUT station is located, is to a high degree satisfied by natural gas, due to large own natural gas reserves under the main land as well as under the North Sea, exploited since the early 1960s. This makes the country's fossil fuel mix unique with respect to its oxidative ratio.

A global carbon budget reconstruction needs long term observations at many stations in order to come to well-founded global mean values. Downscaling to a more regional assessment of the carbon budget needs a high resolution in the sampling sites' distribution, especially if one wants to infer the spatio-temporal distribution of the sources and sinks starting from concentration observations. The first records of atmospheric $\mathrm{CO}_{2}$ concentration measurements were gained from whole-air flask samples (and later on-site continuous instruments), taken on remote, so-called clean-air stations with little continental and thus anthropogenic influence. Only in the 1990s more stations in the interior of the continents became operational, in order to study the rather undiluted biospheric and anthropogenic signals. In general the same strategy was followed when the measurement of the stable isotopologues of $\mathrm{CO}_{2}\left({ }^{13} \mathrm{CO}_{2}\right.$ and $\mathrm{CO}^{18} \mathrm{O}$ ), became more common (Tans et al., 1989, 1990; Ciais et al., 1995). Again for $\mathrm{O}_{2}$ concentration measurements, first the smoother marine background has been investigated, while the stronger but also more locally influenced signals at continental stations came into the picture nearly a decade later (e.g. Keeling et al., 1996; Sturm et al., 2006). From the fossil fuel usage statistics we can expect a certain long-term decrease in the atmospheric $\mathrm{O}_{2}$ concentration, as $\mathrm{O}_{2}$ is transferred into $\mathrm{CO}_{2}$ during combustion. This slow process, as compared to the total abundance of $\mathrm{O}_{2}$, has been observed at many places on Earth during the last decades (Bender et al., 1996; Keeling et al., 1996; Langenfelds et al., 1999; Manning et al., 2003; Manning and Keeling, 2006; Sturm et al., 2005b; Tohjima et al., 2008). 
Atmospheric $\mathrm{CO}_{2}$ and $\mathrm{O}_{2}$ fields can be simulated using global or regional atmospheric transport models based on (re)analyzed meteorological data, with prescribed $\mathrm{CO}_{2}$ and $\mathrm{O}_{2}$ exchange at the Earth surface. While there are measurement-based $\mathrm{CO}_{2}$ and $\mathrm{O}_{2}$ flux data sets for the ocean, and temperature-dependent in- and outgassing of $\mathrm{O}_{2}$ and $\mathrm{N}_{2}$ is taken into account, the incorporation of the terrestrial biosphere mainly depends on biosphere models, carrying their own uncertainties. However, the contribution of the terrestrial biosphere can be removed from the measured data set as well as from the model results. For the models, just no biospheric contribution is taken into account, the total signal is the sum of oceanic and combustion-derived fluxes. For the measured data this means that the variations in $\mathrm{O}_{2}$ concentration are removed from the record as far as they are mirrored by changes in $\mathrm{CO}_{2}$ concentrations (multiplied by the biospheric OR). This is equivalent to the introduction of the tracer "Atmospheric Potential Oxygen" (APO; Stephens, 1999). For the measured data here the problem arises that fossil fuel derived $\mathrm{CO}_{2}$ cannot be distinguished from biospheric $\mathrm{CO}_{2}$ production, if no other ancillary measurements are used. The modelled APO can of course account for this fossil fuel contribution as an extra signal, but an erroneous estimate of the fossil fuel sources' seasonal variability would again be able to mask a realistic simulation of the transport models.

For clean air stations there should be no problem on short timescales, as the actual fossil fuel contribution is generally low, however, continental stations might always suffer from the fact that the fossil fuel contribution is not handled correctly for the APO calculation. On interannual timescales any spatial scale will be concerned. With the OR of the fossil fuel mix becoming higher, e.g. 1.7 on average in the case of the Netherlands, increasing errors would be introduced into the APO dataset. The $\mathrm{O}_{2}$ and $\mathrm{CO}_{2}$ observations at Lutjewad can deliver fundamental constraints especially in view of the final goal of establishing the $\mathrm{CO}_{2}$ emission budget at a national level.

We present here the first five years of atmospheric $\mathrm{O}_{2} / \mathrm{N}_{2}$ ratio and $\mathrm{CO}_{2}$ concentration measurements from whole air flask sampling at Lutjewad and Mace Head and subsequent analysis in the atmospheric laboratory of the Centre for Isotope Research (CIO) of the University of Groningen. All the results presented from Lutjewad are also compared to Mace Head data, in order to highlight the different seasonal patterns and the gradients occurring between the two stations. At Mace Head the dilution of the continental signals justifies the assumption that the APO seasonality is due mainly to oceanic processes such as solubility and the biological pump. The APO seasonal cycle characteristics of the two stations are reported here as well and compared to model expectations.

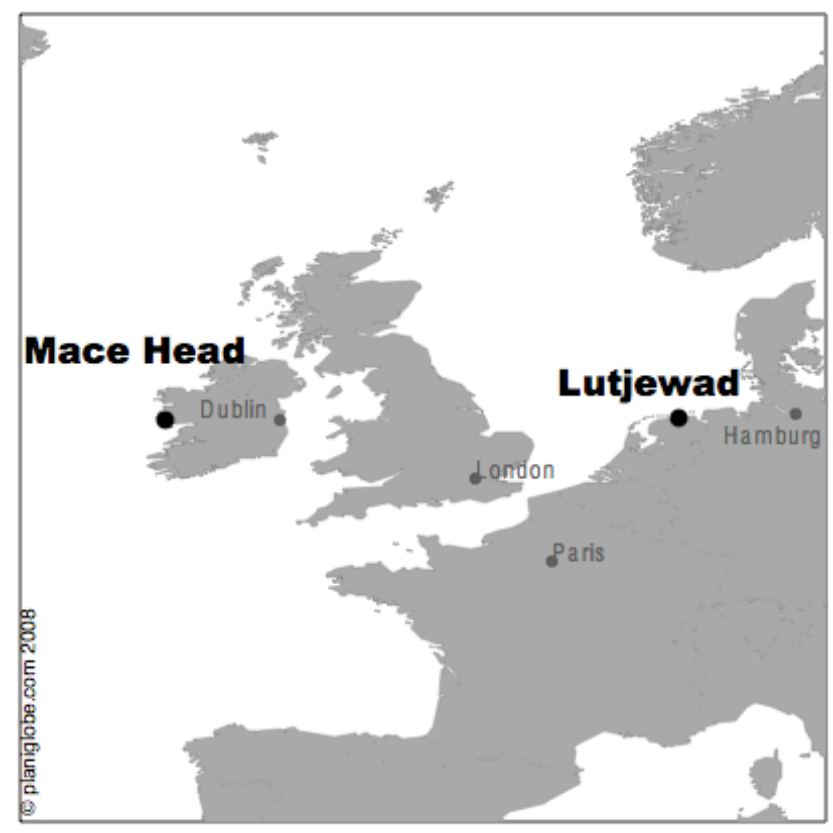

Fig. 1. The sampling sites Mace Head (MHD) and Lutjewad (LUT) in Western Europe (map produced under creative commons license by www.Planiglobe.com).

\section{Sampling stations and measurement techniques}

In order to derive the concurrent variability of both the $\mathrm{O}_{2}$ and $\mathrm{CO}_{2}$ signals at Lutjewad due to terrestrial influences, for this study we chose Mace Head, Ireland $\left(53^{\circ} 20^{\prime} \mathrm{N}, 9^{\circ}\right.$ $54^{\prime} \mathrm{W}, 35 \mathrm{~m}$ a.s.l., operated by the Physics Department at the National University of Ireland, Galway), a marine boundary layer station on the west coast of North Western Europe as a European background monitoring site to compare Lutjewad with. Mace Head station is located in the County of Galway on Ireland's western coast. For a detailed description of the site and its location we refer to Derwent et al. (2002). The air samples were exclusively taken during Restricted Baseline Conditions (RBC, cf. Bousquet et al., 1996), i.e. during periods with wind directions within the sector from $210^{\circ}$ to $290^{\circ}$ and wind velocities higher than $4 \mathrm{~ms}^{-1}$, or with wind directions within the sectors $200^{\circ}$ to $210^{\circ}$ and $290^{\circ}$ to $300^{\circ}$ and wind velocities higher than $8 \mathrm{~ms}^{-1}$, in order to sample just North Atlantic marine air masses. Cryogenically dried air has been sucked into the same type of flasks as in use at Lutjewad, filled to atmospheric pressure. Two samples were collected simultaneously every week if the RBC were met and logistics was permitting.

Station Lutjewad, $\left(53^{\circ} 24^{\prime} \mathrm{N}, 6^{\circ} 21^{\prime} \mathrm{E}\right.$, operated by CIO, University of Groningen), on the northern coast of The Netherlands and $30 \mathrm{~km}$ to the North-West of the city of Groningen (Fig. 1), at nearly the same latitude as MHD, serves as a continental station, also receiving "marine background" air with northerly winds in case of a long North Sea 
fetch (Neubert et al., 2005). While located on the northern coast, the site is characterized by prevalent south-westerly and westerly winds, bringing air masses to the tower coming mainly from the north-western part of the European continent, frequently after close contact to the land surface in The Netherlands and to a lesser extent also the surrounding countries (cf. van der Laan et al. (2009b) for the wind statistics of 2006-2009). The station is equipped with a $60 \mathrm{~m}$ tall tower, with air intakes and basic meteorological equipments at different heights, and a research laboratory.

Basic meteorological measurements at the station include: temperature, relative humidity and wind speed at $7 \mathrm{~m}, 40 \mathrm{~m}$ and $60 \mathrm{~m}$ heights, wind direction (at $60 \mathrm{~m}$ ), atmospheric air pressure and precipitation measurements.

Air is collected from the top of the mast and sucked to the laboratory through about $100 \mathrm{~m}$ of $9.53 \mathrm{~mm}$ i.d. polyethylene-coated aluminium Dekoron "Synflex 1300" tubing at $21 \mathrm{~min}^{-1}$. The air is cryogenically dried at $-55^{\circ} \mathrm{C}$ and flushed through one out of a manifold of twenty 2.51 glass flasks fitted with two Louwers-Hapert high vacuum stopcocks, sealed with viton o-rings. The drying and sampling process is remotely controlled by means of an automated system as described by Neubert et al. (2004). We avoid any influences of the membrane pump on the air sample by placing the pump in the air flow behind the flasks. The flask flushing time normally was set to one hour, and the flasks were filled cyclically one after the other, replacing the "oldest" sample air, unless a certain flask had been blocked remotely by operator intervention in order to keep the air for later analysis in the CIO laboratory. We avoided T-junctions, both in the sample collection and in the sample measurements systems, in order to prevent any fractionation due to pressure and temperature gradients (Stephens et al., 1998, 2007; Manning et al., 2001; Sturm et al., 2006). The flasks were filled to the actual atmospheric pressure in order to keep permeation rates through the viton o-rings during storage time low (Sturm et al., 2004).

For this study, in general one pair of air samples has been taken per week. The sampling time was usually in the afternoon hours, when the vertical atmospheric mixing is maximal. In the beginning, the flask pairs have been taken simultaneously by an occasionally present, on-site operator, but starting from April 2004 onwards the flasks have been taken remote-controlled one at a time, with one or two hours difference. As no remotely accessible analyzer for $\mathrm{CO}_{2}$ concentrations had been available at that time, sampling took place mostly according to the general meteorological situation. Our research aims included the analysis of source characteristics, thus the sampling strategy was not exclusively tuned on "clean" background air samples, e.g. marine air from northerly directions with high windspeed. That is why some samples even from daytime hours comprise high locally-influenced concentration levels and were excluded from the analysis at hand.
The regular laboratory sample handling for flask samples from both stations consisted of mass spectrometric $\mathrm{O}_{2} / \mathrm{N}_{2}$ ratio determination followed by a gas chromatographic analysis of the $\mathrm{CO}_{2}, \mathrm{CH}_{4}$ and $\mathrm{CO}$ concentrations. From a subset of the samples $\mathrm{CO}_{2}$ could be extracted and analyzed for its stable isotope ratios $\delta^{13} \mathrm{C}$ and $\delta^{18} \mathrm{O}$, and eventually $\Delta^{14} \mathrm{C}$, as part of the routine practice. The atmospheric $\mathrm{O}_{2}$ concentration was determined by analyzing the $\mathrm{O}_{2} / \mathrm{N}_{2}$ ratio as a proxy, by a dual inlet isotope ratio mass spectrometer (DI IRMS), a Micromass Optima, following a procedure adapted from Bender et al. (1994). Measurements of $\mathrm{O}_{2} / \mathrm{N}_{2}$ were made as the ratio of mass/charge $(\mathrm{m} / \mathrm{z})$-numbers $32 / 28$ on the main isotopologues of both gases, and compared to the ratio of a machine reference gas in order to derive a $\delta$-value (shortly addressed as $\delta\left(\mathrm{O}_{2} / \mathrm{N}_{2}\right)$ in the rest of this paper), expressed in per meg, with 1000 per meg being equal to $1 \%$ deviation of the ratios:

$$
\begin{aligned}
& \delta\left(\mathrm{O}_{2} / \mathrm{N}_{2}\right)_{\text {sample_vs_mach.ref. }}(\text { permeg }) \\
& =\left(\frac{\left(\frac{\mathrm{O}_{2}}{\mathrm{~N}_{2}}\right)_{\text {SAMPLE }}}{\left(\frac{\mathrm{O}_{2}}{\mathrm{~N}_{2}}\right)_{\text {mach.ref. }}}-1\right) \cdot\left(10^{6}\right)
\end{aligned}
$$

with a variation by $1 \mathrm{ppm}$ of $\mathrm{O}_{2}$ in the atmospheric concentration roughly corresponding to a change of 4.8 per meg.

The instrument was used with the standard metal sample handling and inlet system. In the beginning the flasks were connected one after the other, in 2004 we added a homebuilt inlet manifold including automatic actuators to be put on the flask valves. This way, the evacuation of the inlet ports and the opening of the flasks to the inlet manifold could be controlled by the mass spectrometer software and all flask samples experienced the same timing for the exposure to the mass spectrometer inlet. Each measurement consisted of 16 consecutives switches between gas inlet from resp. reference and sample bellows. The switching of the change-over valves disturbed the signals on the desired precision scale in a way that each switching was followed by $120 \mathrm{~s}$ of idle time, before the actual signal was integrated for $30 \mathrm{~s}$. Samples were measured in batches bracketed by standard measurements. Before admitting sample gas from a cylinder into the sample or reference bellow, air that had been sitting in the pressure regulator for a certain time (different for the different types of gases) was flushed to a waste pump through the inlet system. Instead of fully relying on the machine reference gas, as normally is done in stable isotope analysis by dual inlet mass spectrometry, we used a suite of up to three calibration gases, measured against the same machine reference gas, for external calibration purposes. By doing so, small changes in the instrument's response to the machine reference gas (eventually induced e.g. by slow temperature changes in the laboratory) could be detected and corrected for. However, we lack an internationally recognized $\mathrm{O}_{2}$ concentration (or 
rather $\mathrm{O}_{2} / \mathrm{N}_{2}$ ratio) scale. Therefore we express our results on our internal scale as defined by the primary whole air cylinder number " 2534 ". While in the very beginning this cylinder served as machine reference gas, it was used as calibration gas later on and the scale propagated to a suite of calibration cylinders. Samples taken at Lutjewad or Mace Head have been measured in random order and alternating to each other during the entire period considered for this analysis. The $\delta \mathrm{O}_{2} / \mathrm{N}_{2}$ results referred to these two stations therefore belong to the same internally defined "CIO" $\mathrm{O}_{2}$ scale. The implementation of a common scale is urgently required by the entire $\mathrm{O}_{2}$ community (Worthy and Huang, 2005; Miller, 2006), and CIO is presently involved in different intercomparison exercises with other institutions of this community. The largest intercomparison programme, the "GOLLUM" programme (Global Oxygen Laboratories Link Ultra-precise Measurements; Miller, 2006), involves twelve institutes running high precision $\delta \mathrm{O}_{2} / \mathrm{N}_{2}$ measurement, with the final aim of being able to tie all the measurements to a common scale.

The concentrations of $\mathrm{CO}_{2}$, as well as those of methane $\left(\mathrm{CH}_{4}\right)$ and carbon monoxide $(\mathrm{CO})$ used to decide on locally contaminated samples, were measured by a gas chromatograph (GC, HewlettPackard model 6890N). The instrument had been set up and adapted to the special requirements according to Worthy et al. (2003) and references herein. $\mathrm{CO}_{2}$ and $\mathrm{CH}_{4}$ were separated using a 4 feet long Haysep Q packed column and detected by a Flame Ionization Detector (FID), $\mathrm{CO}_{2}$ after being converted to methane in a nickel-catalyst with hydrogen. For the separation of $\mathrm{CO}$ a different line was employed with a unibeads pre-column and a mol-sieve analytical column, another nickel catalyst methanizer for the conversion of $\mathrm{CO}$ to $\mathrm{CH}_{4}$ and a FID. As the flasks had been filled to atmospheric ground level pressure to minimize permeation effects through the valves' o-rings (Sturm et al., 2004), the flask air needed to be sucked through the GC inlet sample loops by a small membrane pump, situated right before the gas exhaust. A working standard, carefully calibrated against a set of World Meteorological Organization (WMO) standards (Zhao and Tans, 2006 and references therein), was measured after every two samples to normalize the analysis results, in combination with a second gas measured after the flasks. A target gas, measured between the first and the second measurement of a set of eight samples and in the end of a sequence, guarded the quality (accuracy and repeatability) of the flask run. The operational details of the GC (e.g. flow schemes and flow rates of carrier gases) were the same as have been applied in the GC described by van der Laan et al. (2009a), with the exception that the GC applied for the measurements in the present work had separate lines and FIDs for $\mathrm{CO}_{2}$ and $\mathrm{CH}_{4}$ resp. $\mathrm{CO}$, instead of leading the sample through another valve to the same methanizer and detector.

The $\mathrm{CO}_{2}$ concentration is finally expressed as mole fraction and further on in this publication given in parts per million (ppm), being equivalent to $\mu \mathrm{mol} \cdot(\mathrm{mol} \text { dry air })^{-1}$. The
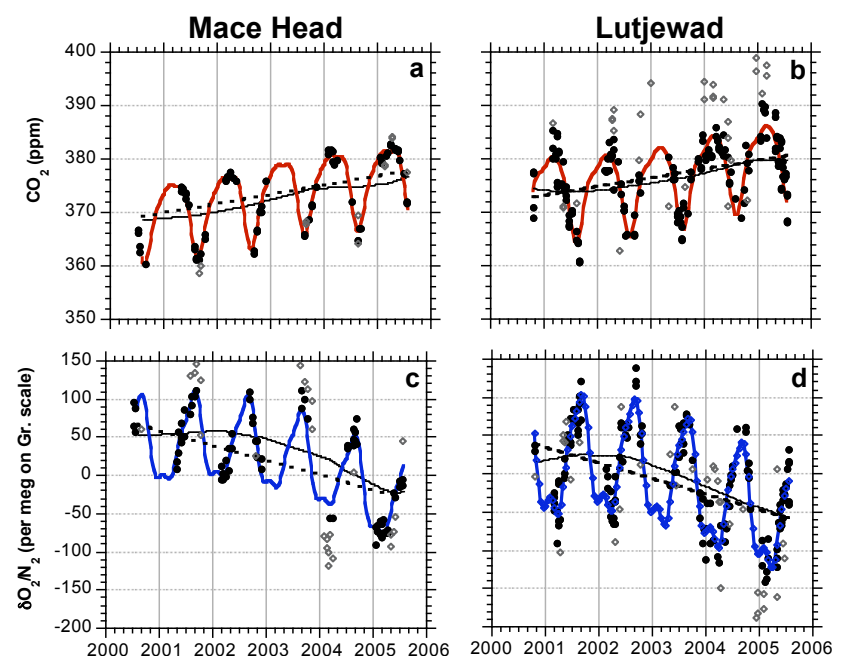

Fig. 2. $\mathrm{CO}_{2}$ concentrations $(\mathbf{a}, \mathbf{b})$ and $\mathrm{O}_{2} / \mathrm{N}_{2}$ ratios $(\mathbf{c}, \mathbf{d})$ records at the stations Lutjewad (a, c) and Mace Head (b, d). The solid lines are a linear combination of three harmonics and a trend function, fitted through the observations. The dashed line represents the average trend while the thin black line is the Loess component (trend) of the fit. Empty symbols are the observations considered outliers according to the procedure described in the text.

CIO laboratory is taking part in WMO $\mathrm{CO}_{2}$ Round Robin exercises and the CarboEurope-IP intercomparison schemes.

The average difference of the flask samples in pairs from Mace Head, measured during the studied period, has been estimated to be $3 \pm 19$ per meg for $\delta \mathrm{O}_{2} / \mathrm{N}_{2}$ and $0.0 \pm 0.5 \mathrm{ppm}$ for $\mathrm{CO}_{2}$ concentrations. This is an extreme estimate of the uncertainty of each given data point including all stages, from sampling, via storage, to the final measurements, the latter typically done on four different days, i.e. two measurements per flask.

\section{Data selection}

The $\mathrm{O}_{2} / \mathrm{N}_{2}$ ratio and $\mathrm{CO}_{2}$ concentration records at Lutjewad and Mace Head started routinely in 2000 and are shown in Fig. 2. After removing obviously contaminated samples, the data have been screened for highly locally influenced air samples, and all the samples with $\mathrm{CO}$ concentrations higher than $300 \mathrm{ppb}$ or $\mathrm{CH}_{4}$ concentrations higher than $2000 \mathrm{ppb}$ were removed from the analyzed record as well. Those samples are representing real ambient concentrations at the respective stations (mainly occurring at Lutjewad), but as we are aiming on a regional analysis, we do not consider them for the data processing. Furthermore, at Lutjewad only samples taken between 08:00 $\mathrm{h}$ and 18:00 $\mathrm{h}$, local time, have been selected, thereby excluding all kind of samples collected for other purposes, e.g. diurnal cycle analysis. Thereafter, an iterative procedure has been applied to eliminate outliers from the prevailing data body. The iterative procedure consisted 
of two nested loops. An inner loop was aimed to find the best least squares fit to the data. The fitting curve used is a linear combination of a harmonic series and a "weighted smooth" or "Loess" trend (Cleveland et al., 1990; Nakazawa et al., 1997 and references therein), according to the "general linear least squares" method (Press et al., 1992). The harmonic series is the sum of the first three harmonics of the annual seasonal cycle, while the smoothing factor of the trend component has been chosen so that the time response was longer than a year. In the inner loop, the "de-trended" data (measurements minus the trend fit) were fitted with the seasonal component and the "de-seasonalized" data (measurements minus the harmonic series) with the trend component. This procedure was alternatively repeated, until no significant variation in the seasonal curve shape occurred. In the outer loop, the residuals between the measurements and the best fit were computed and those data, whose residuals from the fit were larger than $2 \sigma$ of the residuals' distribution, were excluded and considered anomalies. The retained data passed to the inner loop to be refitted again. The sequence was repeated until no further outlier was found.

For Lutjewad, from a total number of 202 and 199 measured samples $\left(\mathrm{CO}_{2}\right.$ resp. $\left.\mathrm{O}_{2}\right) 156$ resp. 144 data points could be retained for the trend and phase analysis. For Mace Head $99\left(\mathrm{CO}_{2}\right)$ resp. $84\left(\mathrm{O}_{2}\right)$ samples were retained out of a total number of 114. The higher rejection rate for $\mathrm{O}_{2} / \mathrm{N}_{2}$ results, especially during the first years, reflects the fact that those measurements are more delicate. As mentioned above, highly locally influenced samples were rejected, leading to $13 \%$ rejections even from Mace Head and 23\% at Lutjewad (both counted for $\mathrm{CO}_{2}$ ). Cutting the clusters of high Mace Head $\mathrm{O}_{2}$ values in the peaks of 2001 and 2003, as well as low $\mathrm{O}_{2}$ values in the beginning of 2004, might wrongly remove phases of extraordinarily strong ocean release resp. uptake, not captured in other years.

This procedure results in a constant seasonal amplitude and phasing for both $\mathrm{CO}_{2}$ concentrations and $\mathrm{O}_{2} / \mathrm{N}_{2}$ ratios. We are aware of the existence of inter-annual variations in the seasonal amplitude as well as in the trend, as has been shown by Bacastow et al. (1985) and Keeling et al. (1995), however, our measurement record so far is too short to allow for a meaningful analysis of these variations.

\section{Analysis, results and discussion}

\section{1 $\mathrm{O}_{2}$ and $\mathrm{CO}_{2}$ time series}

Figure $2 \mathrm{a}$ and $\mathrm{b}$ show the $\mathrm{CO}_{2}$ concentrations expressed in ppm notation at the two stations, while the $\mathrm{O}_{2} / \mathrm{N}_{2}$ ratio records are given as $\delta \mathrm{O}_{2} / \mathrm{N}_{2}$ in per meg, in panels $2 \mathrm{c}$ and d. The results of the data analysis are plotted representing the selected data as filled symbols, the rejected outliers as open symbols, the combined curve fit with three harmonics and the Loess trend as coloured solid line, the Loess trend
Table 1. Amplitude and phase parameters of the seasonal component of the fit to the observed values of $\mathrm{CO}_{2}$ concentrations and $\mathrm{O}_{2} / \mathrm{N}_{2}$ ratios at both studied stations.

\begin{tabular}{|c|c|c|c|c|}
\hline & $\begin{array}{l}\text { peak-to-trough } \\
\text { amplitude }\end{array}$ & $\begin{array}{l}\text { Calenda } \\
\text { min }\end{array}$ & $\begin{array}{l}\text { day of } \\
\max \end{array}$ & $\begin{array}{l} \pm \\
\text { days }\end{array}$ \\
\hline $\mathrm{CO}_{2}$ Mace Head & $14.4 \pm 0.3 \mathrm{ppm}$ & 27 Aug & $26 \mathrm{Feb}$ & 3 \\
\hline $\mathrm{O}_{2}$ Mace Head & $113 \pm 5$ per meg & 14 Mar & $8 \mathrm{Sep}$ & 4 \\
\hline $\mathrm{CO}_{2}$ Lutjewad & $16.1 \pm 0.4 \mathrm{ppm}$ & 14 Aug & $7 \mathrm{Mar}$ & 3 \\
\hline $\mathrm{O}_{2}$ Lutjewad & $153 \pm 3$ per meg & 28 Mar & $11 \mathrm{Sep}$ & 3 \\
\hline
\end{tabular}

alone as thin solid line and an average linear trend as a dotted line. All the records show a significant seasonality with sharp summer peaks and broader (i.e. longer) winter ones with a double-peak structure, typical for the northern location of the sites, characterized by a relatively short growing season. The parameters describing the seasonal patterns are listed in Table 1. For each species, we report the total amplitude of the fitting curve and the days of the year when the maxima and minima occur, as plotted in Fig. 2. The uncertainty associated with each parameter is based on a simpler fitting scheme with a linear component, instead of the Loess trend, and the periodicity represented just by the fundamental harmonic of the seasonal cycle. The uncertainties are then the standard errors of the fit parameters (Press et al., 1992). The remaining scatter of the data is the combination of measurement errors, residual local noise left in the filtered data set and the intrinsic variability of the signals themselves.

The buffer capacity of the ocean and the thermal outgassing, which is in counter-phase with the marine biological activity, dampen the seasonal variations of the $\mathrm{CO}_{2}$ fluxes from and to the atmosphere, so that practically no ocean seasonality can be found back in the $\mathrm{CO}_{2}$ record. The ocean buffer, however, does not affect $\mathrm{O}_{2}$ exchange processes at all; consequently, the $\mathrm{O}_{2}$ seasonality is given by the combination of both terrestrial and marine processes. Marine processes, however, show in the atmosphere a slower response to seasonal changes than the terrestrial ones. On the one hand side, the system ocean-atmosphere shows a typical time lag of 22 days for $\mathrm{O}_{2}$ between the response and the seasonal biological forcing that caused it. This is due to the presence of a finite air-sea interface and a not infinite gas exchange velocity at this interface (Keeling et al., 1993). On the other hand side, the atmosphere directly receives the fluxes occurring at the land interface. Both processes are primarily driven by solar radiation, but still can have a relative phase shift, e.g. caused by a dampened temperature-curve of the ocean. From soil respiration, a certain time-shift might be expected between $\mathrm{O}_{2}$ uptake and $\mathrm{CO}_{2}$ release, but not much is known about this yet. So in general, the $\mathrm{O}_{2}$ record mirrors the $\mathrm{CO}_{2}$ oscillations, but with a delay caused by the influence of the marine biological fluxes superimposed to the land biota ones, as 
shown by both station's records. At Lutjewad the $\mathrm{CO}_{2}$ concentration has its minimum in the middle of August (around 14 August), and it increases towards the maximum around 7 March, mainly under the influence of terrestrial biosphere processes. The Lutjewad $\mathrm{O}_{2}$ minimum occurs around 28 March and the maximum on 11 September.

The Mace Head record depicts similar patterns, with small phase leads or lags, as the early winter $\mathrm{CO}_{2}$ peak (on 26 February) or the later summer trough (on 27 August). $\mathrm{O}_{2}$ reaches its highest concentration around 8 September, almost simultaneously to Lutjewad, and has its minimum around 14 March, two weeks later. A possible explanation could be the different origin of the terrestrial biospherical sources seen in the air masses sampled at Mace Head, compared to those of Lutjewad. The two stations, though located at the same latitude, sample different kinds of air masses, because of the sampling strategy and the wind distribution. In Lutjewad no distinct air-sampling selection has been applied, while samples at Mace Head have been taken under conditions aimed to sample just North Atlantic air masses. At Mace Head, the $\mathrm{CO}_{2}$ record shows earlier and longer winter features and a more abrupt change from winter to summer and vice versa, as compared to Lutjewad. As the RBC strategy is meant to avoid the sampling of local air masses, the terrestrial signals here are derived from long-range transport (thus from the American Continent) and are representative for the average conditions along the 53rd degree of latitude. Arriving at Lutjewad, air masses have been influenced by local and regional land-based sources and sinks (e.g. England and France) where the climate is mitigated by the effects of the Gulf stream. We can therefore argue that this difference appears in the $\mathrm{CO}_{2}$ record as if Lutjewad was located more to the south regarding terrestrial influences.

The $\mathrm{CO}_{2}$ concentration has in Lutjewad an annual peakto-trough amplitude of $(16.1 \pm 0.4) \mathrm{ppm}$, while the annual $\delta \mathrm{O}_{2} / \mathrm{N}_{2}$ amplitude is (153 \pm 3$)$ per meg. The remoteness from land sources of Mace Head sampled air can be observed in our records in the dampening of both species' seasonal amplitude: (14.4 \pm 0.3$) \mathrm{ppm}$, peak-to-trough amplitude for $\mathrm{CO}_{2}$ and (113 \pm 5$)$ per meg for $\mathrm{O}_{2} / \mathrm{N}_{2}$, due to the dilution of the signals through the atmospheric mixing. This dilution could also be due to different seasonal variations of the resp. atmospheric boundary layer heights, causing an enhanced "rectifier effect" (e.g. Denning et al., 1999) in the records seen at Mace Head, as compared to those at Lutjewad. This dampening in the signals is even more evident when comparing them with those from two other (semi-)continental stations in Europe like Puy de Dome in France $\left(45^{\circ} 46^{\prime} \mathrm{N}, 2^{\circ}\right.$ $58^{\prime}$ E, $1480 \mathrm{~m}$ a.s.1.) (Sturm et al., 2005b), and Griffin Forest $\left(56^{\circ} 37^{\prime} \mathrm{N} 3^{\circ} 47^{\prime} \mathrm{W}, 800 \mathrm{~m}\right.$ a.s.l.), in Scotland (Sturm et al., 2005a). While the first one is a ground site at large height in Central France, the second one is an aircraft site above a forest in the east of Scotland, both without marine air sample selection. Here, higher amplitudes than at Lutjewad or Mace $\mathrm{Head}$ have been recorded for both species. Peak-to-peak $\mathrm{O}_{2}$
Table 2. The trends and their uncertainties during the studied period at both stations. $\mathrm{CO}_{2}$ trends are given in per ppm $\mathrm{y}^{-1}$ and $\mathrm{O}_{2}$ trends are given in $\mathrm{meg}^{-1}$.

\begin{tabular}{|c|c|c|c|c|}
\hline & $\begin{array}{l}\mathrm{CO}_{2} \\
\mathrm{LUT}\end{array}$ & $\begin{array}{l}\mathrm{CO}_{2} \\
\mathrm{MHD}\end{array}$ & $\begin{array}{l}\mathrm{O}_{2} \\
\mathrm{LUT}\end{array}$ & $\begin{array}{l}\mathrm{O}_{2} \\
\mathrm{MHD}\end{array}$ \\
\hline $\begin{array}{lll}\text { Jul } & 00 & \ldots \\
\text { Jul } & 05\end{array}$ & $1.7 \pm 0.2$ & $1.7 \pm 0.1$ & $-20 \pm 1.5$ & $-19 \pm 1.5$ \\
\hline $\begin{array}{l}\text { Jan } 02 \quad \ldots \\
\text { Jan } 05\end{array}$ & $1.6 \pm 0.5$ & $1.9 \pm 0.2$ & $-27 \pm 3$ & $-25 \pm 4$ \\
\hline
\end{tabular}

seasonal amplitudes have been reported to be 190 per meg and 171 per meg, at Puy de Dome and even from aircraft sampling above Griffin Forest, respectively. $\mathrm{CO}_{2}$ peak-topeak seasonal amplitudes are reported to be $18.2 \mathrm{ppm}$ and $17.6 \mathrm{ppm}$ for the two stations, respectively. Mixing phenomena leading to dilution of air masses with free tropospheric air are indicated by the shrink in the amplitudes reported for the high-alpine station Jungfraujoch (Switzerland) by Sturm et al. (2005b), compared to those we found at the two costal stations under investigation here.

\subsection{Trends and interannual variability}

The average trend (shown by a dotted line in Fig. 2) is derived from a fit through the selected data. The fitting curve includes a series of the first three harmonics of the annual cycle as seasonal component, but it has a linear trend component instead of the Loess one. In order to compare these average trends between the two stations, the same period, from July 2000 to July 2005, has been chosen for the fit. From this analysis it resulted that, at Lutjewad, $\mathrm{CO}_{2}$ increased by $(1.7 \pm 0.2) \mathrm{ppm} \mathrm{y}^{-1}$, while $\mathrm{O}_{2}$ changed by $(-20 \pm 1.5)$ per meg $\mathrm{y}^{-1}$. Comparable trends have been obtained for Mace Head: $(1.7 \pm 0.1) \mathrm{ppm} \mathrm{y}^{-1}$ for $\mathrm{CO}_{2}$ and $(-19 \pm 1.5)$ per meg $\mathrm{y}^{-1}$ for $\mathrm{O}_{2}$. These trends are mainly caused by human interferences on the natural cycles, such as combusting fossil fuels, that cause the atmospheric $\mathrm{CO}_{2}$ level to rise and a proportional decrease of $\mathrm{O}_{2}$. The $\mathrm{O}_{2}$ trend shows a faster decrease compared to the trend observed at other sites for the previous years. The mean global annual $\mathrm{O}_{2}$ decrease was 15.6 per meg y $^{-1}$ from 1990 to 2000 (Prentice et al., 2001). The $\mathrm{CO}_{2}$ trend seems also to have increased compared to the $1.51 \mathrm{ppm} \mathrm{y}^{-1}$ average annual trend for the period 1990 to 2000 (Prentice et al., 2001), though the uncertainties on the estimates don't allow for a significant distinction. We can argue that both those trend accelerations seem to be consistent with a faster increase in the use of fossil fuel, especially because of the fast growing economy of the Far East countries (Raupach et al., 2007).

$\mathrm{CO}_{2}$ and $\mathrm{O}_{2}$ growth rates are highly variable from year to year, as can also be seen from the comparison between the 

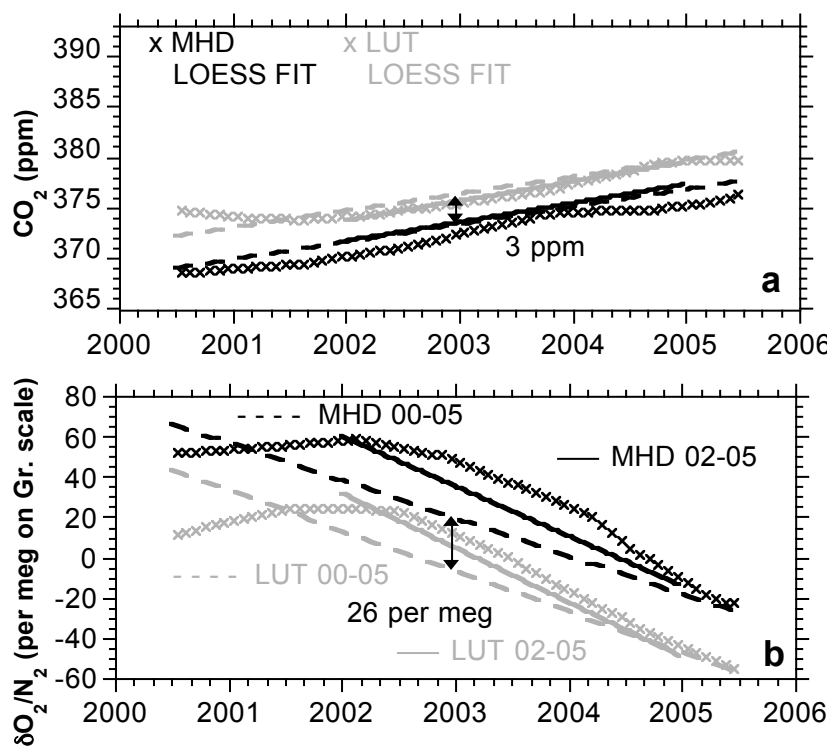

Fig. 3. The variability in the trends of $\mathrm{CO}_{2}$ concentrations and $\mathrm{O}_{2} / \mathrm{N}_{2}$ ratios trends at Mace Head and Lutjewad, according to fit procedure and period.

linear and Loess trend. Unfortunately, the records presented here show the start up of the measurement series. They suffer from some data gaps and are still quite short if we want to deduce the long term behaviour, and too short to characterize the interannual variability, in both growth rate and seasonal amplitudes. This data set is definitely not suitable for a yearto-year based analysis of the growth rate of the two species. Nevertheless, we can clearly detect differences between the two locations and show variations in the trends of $\mathrm{CO}_{2}$ and $\mathrm{O}_{2}$ along the considered period. Given the short time span of our atmospheric records, we want to address here how strongly the choice of a certain time range within a given period can influence the trend estimate, especially with a not fully constrained data set as this one. Figure 3 displays with dashed lines the average trend derived for the entire period (July 2000 to July 2005) as previously described, while solid lines represent the average trend derived in the same way, but for the period January 2002 to January 2005. Crosses represent the Loess component of the fit through the selected data points, as in Fig. 2. Gray tones are used for Lutjewad and black for Mace Head. In panel a, the results for $\mathrm{CO}_{2}$ are presented, while in panel $\mathrm{b}$ those for $\mathrm{O}_{2}$ are shown. All the trends are summarized in Table 2 . The decreasing Loess trend in $\mathrm{CO}_{2}$ (Lutjewad) and the increase in $\mathrm{O}_{2} / \mathrm{N}_{2}$ at both stations in the beginning period cannot be explained by any known atmospheric process. We regard it as marginal effects of the Loess procedure, depending on the starting season and the sample distribution of the early record. Therefore we also separately investigate the period from 2002 until 2005 and present linear trends for this latter period.
If we would apply the budget equations, as in the following section, we could give an estimate of the annual fossil fuel combustion that could have produced such a trend in the airborne $\mathrm{O}_{2} / \mathrm{N}_{2}$ ratio. That is, we could regard the fossil fuel and cement production term as being unknown, while keeping the land uptake constant, staying the same as derived for the entire period 2000-2005. We would then conclude based on Lutjewad measurements, that the amount of $\mathrm{CO}_{2}$ emitted because of industrial processes and fossil fuel burning would have increased on average by more than $2 \mathrm{PgC}^{-1}$, emitted on top of the value $(7.3 \pm 0.5) \mathrm{PgC}^{-1}$ calculated for the period 2000.5-2005.5, while the ocean uptake of anthropogenic carbon would have to almost double compared to the estimates based on the period 2000-2005. We regard this as not being realistic.

Obviously, if we believe these enhanced trends not to be artefacts, we require an extra $\mathrm{O}_{2}$ sink, until now not accounted for in top-down approaches used to reproduce the $\mathrm{O}_{2}$ and $\mathrm{CO}_{2}$ fluxes, following the anthropogenic disturbances. This extra sink, whatever its character might be, would then have increased substantially around 2003. It is likely that this unaccounted sink resides in the terrestrial compartment as recently suggested by Randerson et al. (2006) and Ciais et al. (2007). Accounting for extra sinks of atmospheric $\mathrm{O}_{2}$ alone due to land use change (Randerson et al., 2006) or due to land nitrogen processes (Ciais et al., 2007), would definitely decrease the need for this large ocean sink. While this would be more plausible than the large ocean sink, it is unclear why the suggested alternative mechanisms would not correspond to any comparable variation of the $\mathrm{CO}_{2}$ trend and why it would suddenly become so much more important between 2002 and 2004. The anomalously hot summer of 2003 in Europe, or the recovery period directly afterwards, might be the cause of new, eventually temporary $\mathrm{O}_{2}$ sink mechanisms. However, the relation between the hot and dry summer months of that year, and the mechanisms suggested by Ciais et al. (2007) and Randerson et al. (2006) is yet unclear.

Furthermore, both articles agree that the OR associated to land processes need to be carefully reconsidered. Randerson et al. (2006) assert that it is no longer possible to define a univocal net terrestrial oxidative ratio associated to land biological processes, because of a global human-induced change in the plant coverage that is increasing the oxidation status of the organic matter over time. The oxidative ratio associated to the $\mathrm{CO}_{2}$ fluxes leaving the atmosphere is therefore now different from that related to the fluxes moving from land to the atmosphere, causing a disequilibrium forcing term to appear in the $\mathrm{O}_{2}$ balance. As a consequence, a net $\mathrm{O}_{2}$ sink has to be accounted for in proportion to the $\mathrm{CO}_{2}$ source from the land ecosystems, such as heterotrophic respiration, according to the difference of those oxidative ratios, i.e. increasing the apparent total OR of the source. Ciais et al. (2007) have suggested the existence of another, up to now not accounted for, sink of atmospheric $\mathrm{O}_{2}$. This additional $\mathrm{O}_{2}$ sink is created by human-induced modification of the nitrogen cycle, 
starting from fertilizer production and its addition to croplands and also including combustion of the fertilized organic matter and production of $\mathrm{NO}_{x}$ associated to fossil fuel burning. The first immediate effect is the subtraction of atmospheric $\mathrm{O}_{2}$ because of industrial synthesis of ammonium nitrate fertilizer and because of the nitrification of the other forms of $\mathrm{N}$-fertilizers occurring in the soil. As compared to the $\mathrm{CO}_{2}$-release of these processes, again much more $\mathrm{O}_{2}$ would be used up than would correspond to an OR of 1.1. However it is difficult to explain such an acceleration of the $\mathrm{O}_{2}$ decrease of more than $1 \mathrm{ppm} \mathrm{y}^{-1}$ by means of fluxes that though growing stay relatively small, adding up to no more than few tenths of a ppm of $\mathrm{O}_{2}$ sequestrated from the atmosphere each year. Even more challenging it would be to explain the extreme decrease of $\mathrm{O}_{2}$ recorded inside the continent in the years 2003-2006, as reported for station Jungfraujoch by Valentino et al. (2008). At that point it cannot be concludingly judged if oceanic processes account for this effect, as has been suggested by those authors, or if it could be seen as a further evidence that the land processes are really playing a prominent role in the acceleration of the atmospheric $\mathrm{O}_{2}$ decrease over time. In the latter case, it might be no random coincidence that this extreme uptake of $\mathrm{O}_{2}$ occurs in years characterized by extreme summer events like in 2003 (Ciais et al., 2005), however, the independence of the $\mathrm{CO}_{2}$ signal from the observed $\mathrm{O}_{2}$-decrease would plead in favour of oceanic processes. Most probably all mentioned processes contribute a share to the total result.

Another evident feature in Fig. 3 are the gradients between Mace Head and Lutjewad. In January 2003, $\mathrm{CO}_{2}$ was $3 \mathrm{ppm}$ lower and $\delta \mathrm{O}_{2} / \mathrm{N}_{2} 26$ per meg higher at Mace Head than at Lutjewad. Probably, this gradient can be explained as a result of the dilution of the signals of the anthropogenic processes, as moving away from the continents toward remote marine areas, where just oceanic air masses are sampled. We can also notice that both $\mathrm{CO}_{2}$ and $\delta \mathrm{O}_{2} / \mathrm{N}_{2}$ gradients between Mace Head and Lutjewad tend to increase in the last few years, as described as well by Ramonet et al. (2010) for $\mathrm{CO}_{2}$ during the period 1995 until 2007.

\subsection{Atmospheric Potential Oxygen (APO)}

Following Stephens et al. (1998), APO is a tracer sensitive to ocean-atmosphere exchange of $\mathrm{O}_{2}$ and $\mathrm{CO}_{2}$, but not to biospheric $\mathrm{O}_{2} / \mathrm{CO}_{2}$ exchanges. We apply the slightly adjusted equation, neglecting carbon stored in atmospheric $\mathrm{CH}_{4}$ and CO (Manning and Keeling, 2006):

$\delta \mathrm{APO}=\delta\left(\mathrm{O}_{2} / \mathrm{N}_{2}\right)+\frac{1}{x_{\mathrm{O}_{2}}} \cdot \beta \cdot\left(\mathrm{ppmCO}_{2}-350\right)$

where $\delta\left(\mathrm{O}_{2} / \mathrm{N}_{2}\right)$ is a proxy for the $\mathrm{O}_{2}$ concentration as defined in (1) and actually measured, and $\mathrm{ppmCO}_{2}$ represent the atmospheric $\mathrm{CO}_{2}$ mole fraction in ppm as in Sect. 2, $\mathrm{x}_{\mathrm{O}_{2}}=0.2095$ being the fraction of oxygen in air and 350 the $\mathrm{CO}_{2}$ mole fraction in ppm, as in a standard atmosphere. In

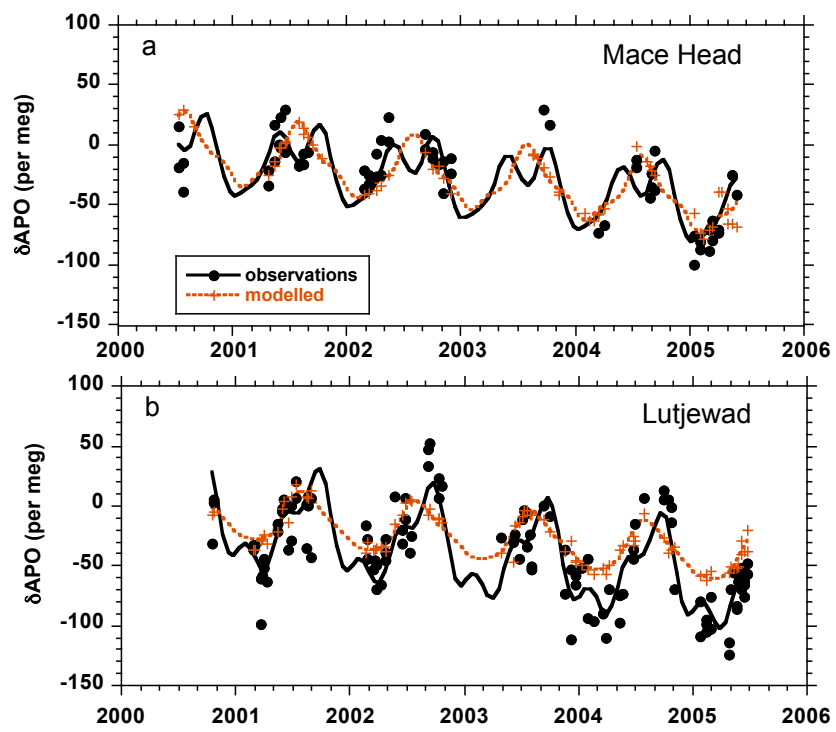

Fig. 4. APO time series at Mace Head (a) and Lutjewad (b). Model outputs, selected at the same sampling time as the observations, are represented by crosses. The fit curves through the model outcomes are plotted with dashed lines.

other words APO is the oxygen that potentially would be in the atmosphere if all its $\mathrm{CO}_{2}$ were used by biological processes occurring on land, with $\beta$ being the OR characterizing all terrestrial biological processes, i.e. photosynthesis and respiration as a whole.

In terms of moles of $\mathrm{CO}_{2}$ and $\mathrm{O}_{2}$ in an air parcel, temporal changes of APO can be described as:

$$
\begin{aligned}
& \frac{d}{d t} \mathrm{APO}=\frac{d}{d t} \mathrm{O}_{2}+\beta \frac{d}{d t} \mathrm{CO}_{2} \\
& =\left(n_{\mathrm{AIR}} \frac{d}{d t} \delta\left(\mathrm{O}_{2} / \mathrm{N}_{2}\right)+\frac{\frac{d}{d t} \mathrm{~N}_{2}}{x_{\mathrm{N}_{2}}}\right) \cdot x_{\mathrm{O}_{2}}+\beta \frac{d}{d t} \mathrm{CO}_{2}
\end{aligned}
$$

The second part of this formulation relates the variations of APO directly to the measured quantity $\delta\left(\mathrm{O}_{2} / \mathrm{N}_{2}\right)$ and, therefore, accounts also for the variability given by changes of the $\mathrm{N}_{2}$ contents in the atmosphere. Here, $n_{\text {AIR }}$ is the total number of moles gas in the global atmosphere and $x_{\mathrm{N}_{2}}=0.7808$ the average nitrogen fraction.

The APO records for Lutjewad and Mace Head have been calculated according to the definition given in Eq. (2), using the data selected with the procedure described in the section "data selection". Therefore only the data selected to be regionally representative for both $\mathrm{CO}_{2}$ and $\mathrm{O}_{2}$ have been chosen. An offset represented by the value at the time 2000.0 of their linear trend has been subtracted from the data in order to express APO variations in a comparable way for both observations and model estimates. The resulting time series have been fitted with a linear combination of the first three harmonic components and a linear trend and are presented in 
Table 3. Parameters of the harmonic fit to the modelled and observed APO at Mace Head and Lutjewad. Amplitude and phase are taken from the curves through the monthly or bimonthly means of detrended APO data, as shown in Fig. 6.

\begin{tabular}{lccc}
\hline & $\begin{array}{c}\text { peak-to-trough } \\
\text { amplitude (per meg) }\end{array}$ & Trend (per meg y & \\
\hline MHD observed & $44 \pm 5$ & $-9.5 \pm 1.7$ & Calendar day of max \\
MHD modelled & $46 \pm 2$ & $-9.3 \pm 0.6$ & $27 \mathrm{Jul} \pm 12$ \\
LUT observed & $70 \pm 5$ & $-12.3 \pm 1.5$ & $2 \mathrm{Aug} \pm 4$ \\
LUT modelled & $42 \pm 2$ & $-8.1 \pm 0.4$ & $2 \mathrm{Aug} \pm 8$ \\
LUT mod. (modif.) & $102 \pm 2$ & $-12.0 \pm 0.6$ & $14 \mathrm{Jul} \pm 2$ \\
\hline
\end{tabular}

Fig. 4, where the samples are plotted as black full circles and the fit curves appear as black solid lines. Panel a refers to Mace Head and panel $b$ refers to Lutjewad. The parameters characterising the fitting curves are summarized in Table 3.

APO varies over time because of all those processes that involve $\mathrm{CO}_{2}$ and $\mathrm{O}_{2}$ with a stoichiometrical relation different from 1.1, otherwise a change in one of the two would produce an opposite change in the other, cancelling it out for APO.

In short, on time scales longer than a year, the variations in APO are prominently due to ocean uptake of $\mathrm{CO}_{2}$, as no comparable oxygen net outgassing occurs in the opposite direction, apart from a small flux of oxygen due to the global increase of the oceans' temperature. Therefore, the secular linear trend of the APO record can be used in order to solve the global carbon budget; an example is given in the next section.

On shorter time scales, oxygen exchanges at the air sea interface play the leading role determining APO seasonal variation, as they are not accompanied by concurrent opposite $\mathrm{CO}_{2}$ fluxes.

In both cases APO is supposed to be a tracer with no or minor sources on land and therefore assumed to be suitable for example as to test atmospheric transport models over the continents. Section 4.3.1 discusses this matter suggesting to be more careful on this assumption.

\subsubsection{Global carbon budget}

Based on long term trends of $\mathrm{O}_{2}$ and $\mathrm{CO}_{2}$, as shown first by Keeling and Shertz (1992), it is possible to estimate the partitioning of the anthropogenic $\mathrm{CO}_{2}$ fluxes from the atmosphere to the oceans and the terrestrial biosphere resp., by simultaneously solving the budgets for the airborne $\mathrm{CO}_{2}$ (Eq. 4) and $\mathrm{O}_{2}$ (Eq. 5) concentration.

If we express these budgets in terms of average growth rates of the number of $\mathrm{CO}_{2}$ and $\mathrm{O}_{2}$ moles in the global atmosphere, broken down into their different components, we write:

$$
\frac{\Delta \mathrm{CO}_{2}}{\Delta t}=\frac{\Delta F}{\Delta t}-\frac{\Delta B}{\Delta \mathrm{t}}-\frac{\Delta O}{\Delta t}
$$

$\frac{\Delta \mathrm{O}_{2}}{\Delta t}=-\phi \cdot \frac{\Delta F}{\Delta t}+\beta \cdot \frac{\Delta B}{\Delta t}+\frac{\Delta Z}{\Delta t}$

where, during a sufficiently long time $\Delta t$, the observed atmospheric $\mathrm{CO}_{2}$ increase and $\mathrm{O}_{2}$ decrease $\left(\Delta \mathrm{CO}_{2} / \Delta t\right.$ and $\Delta \mathrm{O}_{2} / \Delta t$ in the budget equations, respectively) depend on:

the number of moles of $\mathrm{CO}_{2}$ released $(\Delta F / \Delta t)$ and $\mathrm{O}_{2}$ used $(-\phi \cdot \Delta F / \Delta t)$ due to fossil fuel burning and cement manufacturing processes,

the number of moles of the biosphere carbon $(\Delta B / \Delta t)$, i.e. the net number of moles carbon taken up as overall effect of all biological processes occurring on land, and the moles of $\mathrm{O}_{2}$ moved in the opposite direction by the same kind of processes $(\beta \cdot \Delta B / \Delta t)$ and finally,

the moles of carbon sequestered by oceanic processes $(\Delta O / \Delta t)$, uncorrelated with the amount of $\mathrm{O}_{2}$ exchanged at the ocean interface $(\Delta Z / \Delta t)$.

In these equations, $\phi$ and $\beta$ are the molar ratios $\left(\mathrm{O}_{2} / \mathrm{CO}_{2}\right)$ obtained from the stoichiometry of the reactions involving the two molecules; $\phi$ for fossil fuel and cement production, and $\beta$ for biospheric processes. They represent the moles of $\mathrm{O}_{2}$ produced for each mole of $\mathrm{CO}_{2}$ used and vice versa.

We followed the method formalized and extensively described by Manning and Keeling (2006), and, just for comprehensibility, we report here a summary of this procedure.

Accounting for finite variations occurring from year to year $(\Delta t=1 \mathrm{y})$, assuming constant annual rates, we can substitute the airborne $\Delta \mathrm{CO}_{2}$ and $\Delta \mathrm{O}_{2}$ components, given by (4) and (5), into the APO definition Eq. (3):

$\Delta \mathrm{APO}=(\beta-\phi) \cdot \Delta F+\Delta Z-\beta \Delta O$

Finally, the oceanic and terrestrial $\mathrm{CO}_{2}$ uptake can be derived from Eq. (4) and (6), respectively, as follows:

$$
\begin{aligned}
& \Delta O=\frac{1}{\beta}[(\beta-\phi) \cdot \Delta F+\Delta Z-\Delta \mathrm{APO}] \\
& \Delta B=\Delta F-\Delta \mathrm{CO}_{2}-\Delta O
\end{aligned}
$$

We can solve the budgets using the linear trends of each parameter. $\mathrm{CO}_{2}$ released by fossil fuel combustion and cement manufacturing has been $(6.0 \pm 0.4) \times 10^{14} \mathrm{~mol} \mathrm{y}^{-1}$ on average from 2000 until 2006, taken from Boden et al. (2009). 
Table 4. Comparison of different estimates of sources and sinks of $\mathrm{CO}_{2}$ from fossil fuel and cement manufacturing. These estimates are based on observations taken at La Jolla, California (LJO), Alert, Canada (ALT), Cape Grim, Australia (CGO), Hateruma Island (HAT) and Cape Ochi-Ischi (COI) in Japan, and from the stations described in this study.

\begin{tabular}{|c|c|c|c|c|c|}
\hline Period & Stations & $\Delta \mathrm{O}$ & $\Delta B$ & $\Delta F$ & Ref. \\
\hline & & $\left(\mathrm{PgC}^{-1}\right)$ & $\left(\mathrm{PgC}^{-1}\right)$ & $\left(\mathrm{PgC}^{-1}\right)$ & \\
\hline \multirow[t]{2}{*}{ 2000.5-2005.5 } & MHD & $2.4 \pm 0.8$ & $1.3 \pm 1.0$ & $7.3 \pm 0.5$ & this study \\
\hline & & $33 \%$ & $18 \%$ & $100 \%$ & \\
\hline \multirow[t]{2}{*}{ 1993-2003 } & ALT, LJO, CGO & $2.2 \pm 0.6$ & $0.5 \pm 0.7$ & $6.5 \pm 0.5$ & Manning and Keeling (2006) \\
\hline & & $35 \%$ & $8 \%$ & $100 \%$ & \\
\hline \multirow[t]{2}{*}{ 1999.5-2005.5 } & HAT, COI & $2.0 \pm 0.7$ & $1.2 \pm 0.9$ & $7.1 \pm 0.0$ & Tohjima et al. (2008) \\
\hline & & $29 \%$ & $14 \%$ & $100 \%$ & \\
\hline \multirow[t]{2}{*}{ 2000.5-2005.5 } & LUT & $3.4 \pm 0.9$ & $0.3 \pm 1.1$ & $7.3 \pm 0.5$ & this study \\
\hline & & $47 \%$ & $4 \%$ & $100 \%$ & \\
\hline
\end{tabular}

The factor $\beta=1.1 \pm 0.05$ is taken from Severinghaus (1995). The molar ratio $\phi=1.4 \pm 0.1$ is, as in Keeling (1988), the average of the ratios of the four main fossil fuel categories (i.e. natural gas, crude oil and natural gas liquids, coal, and natural gas flaring) weighted by their fractions of the total emissions, during the period 2000-2006 (Boden et al., 2009). The total uncertainty on $\phi$ has been derived assuming for each fossil fuel fraction an uncertainty of 5\%. Secular oceanic $\mathrm{CO}_{2}$ uptake leaves the atmospheric $\mathrm{O}_{2}$ concentration unchanged, but a constant rate of atmospheric $\mathrm{O}_{2}$ increase of $(0.45 \pm 0.45) \times 10^{14} \mathrm{~mol} \mathrm{y}^{-1}$ can be assigned to the $\mathrm{O}_{2}$ net outgassing from the ocean, $\Delta \mathrm{Z}$, in order to take into account the global ocean warming (Levitus et al., 2000). $\Delta \mathrm{CO}_{2}$ and $\triangle \mathrm{APO}$ have been taken as the linear trends of the records reported in this study, found to be $(3.0 \pm 0.4) \times 10^{14} \mathrm{~mol}$ $\mathrm{CO}_{2} \mathrm{y}^{-1}$ and $(-4.4 \pm 0.4) \times 10^{14} \mathrm{~mol} \mathrm{APO} \mathrm{y}{ }^{-1}$, for Lutjewad, and $(3.0 \pm 0.2) \times 10^{14} \mathrm{~mol} \mathrm{CO}_{2} \mathrm{y}^{-1}$ and $(-3.5 \pm 1.0)$ $\times 10^{14} \mathrm{~mol} \mathrm{APO}^{-1}$ for Mace Head.

To convert mole fractions and delta notations to number of moles and vice versa we use a constant number of $1.769 \times 10^{20}$ moles in the global atmosphere, of which $78.08 \%$ are nitrogen and $20.95 \%$ are oxygen. Furthermore, in order to convert the variations of APO into moles, based on the measured $\delta\left(\mathrm{O}_{2} / \mathrm{N}_{2}\right)$ in per meg units (see Eq.(3)), a small correction of $0.05 \times 10^{14} \mathrm{O}_{2} \mathrm{~mol} \mathrm{y}^{-1}$ has been adopted, which accounts for net outgassing of $\mathrm{N}_{2}$ from the ocean due to global warming, assumed to be of $0.2 \times 10^{14} \mathrm{~mol} \mathrm{y}^{-1}$.

For a better comparability with other studies, the number of moles of carbon can be converted to mass by taking the molar mass of carbon as $12 \mathrm{~g} / \mathrm{mol}$.

Using only Mace Head data, we found that from the $(7.3 \pm 0.5) \mathrm{PgCy}^{-1}$ anthropogenic carbon, originating from fossil fuel burning and cement production, (3.6 \pm 0.2$)$ $\mathrm{PgC}^{-1}$ remains airborne, (2.4 \pm 0.8$) \mathrm{PgCy}^{-1}$ is taken up by the oceans and, thus, the rest, being (1.3 \pm 1.0$) \mathrm{PgC}^{-1}$, is sequestered by land biota. Table 4 reports a comparison among this study and the budget solutions proposed by Manning and
Keeling (2006) and Tohjima et al. (2008), with data from comparable periods. The kind of calculation shown above confirms the primary role of the oceanic sink. It mitigates the increase of carbon dioxide in the atmosphere by taking up one third of this anthropogenic carbon, due to fossil fuel combustion and cement production.

All the results agree within the uncertainties, nevertheless the absolute numbers still suggest few considerations. As compared to the period 1993-2003 (Manning and Keeling, 2006), fossil fuel usage has increased over the recent years, however, these budget solutions hint that the oceanic sink is not changed accordingly. On the other hand, the land biospheric processes seem to have promptly responded to this increased anthropogenic emissions by increasing their capability to sequester more carbon each year.

Different considerations have to be given for Lutjewad. The Lutjewad data are more influenced by continental sources and sinks and therefore they are less suited to depict the baseline conditions necessary to reconstruct the global budget. Within the high uncertainties, the findings from the Lutjewad observations are quite similar to those from Mace Head and the other studies, with an oceanic sink of (3.4 \pm 0.9$)$ $\mathrm{PgCy}^{-1}$ and a land sink of $(0.3 \pm 1.1) \mathrm{PgC}^{-1}$. Nevertheless, we clearly observe a larger oceanic sink and, of course, a smaller land sink. Evidences derived also by comparison with model simulations lead to the hypothesis that this could be an artefact caused by an erroneous assumption on characteristics of the fossil fuel signal detected at Lutjewad. The possibility we suggest is the influence of more local fossil fuel sources with a considerably higher OR on the Lutjewad record. In this case, a change of the $\phi$ molar ratio to the higher local value of 1.54, instead of the commonly used 1.39 , would produce together with our Lutjewad observations the same kind of sink partitioning achieved with Mace Head data when applying the global mean $\phi$.

Finally, a possibility that cannot be fully neglected is a calibration artefact that would cause these different trends in 
APO. However, we believe this is not the case, as it would have affected both time series measured during the same period. The $\mathrm{O}_{2} / \mathrm{N}_{2}$ calibration history of the CIO is under review and will be published elsewhere.

\subsubsection{Effects of fossil fuel emissions on APO trend and climatology}

The APO observations have been compared to model simulations based on surface flux fields transported by applying the TM3 atmospheric transport model (Rödenbeck, 2005), with a spatial resolution of $1.8 \times 1.8$ degrees. Each component reported in the APO definition of Eq. (6) has been simulated for both stations and the modelled APO variation has been calculated in terms of concentrations, in order to reproduce the measurements at LUT and MHD, as in Eq. (9).

\section{$\Delta \delta \mathrm{APO}$}

$=(\beta-\phi) \cdot \frac{\Delta F}{n_{\mathrm{AIR}}} \frac{1}{x \mathrm{O}_{2}}+\frac{\Delta \mathrm{Z}}{n_{\mathrm{AIR}}} \frac{1}{x \mathrm{O}_{2}}-\beta \frac{\Delta \mathrm{O}}{n_{\mathrm{AIR}}} \frac{1}{x_{\mathrm{O}_{2}}}-\frac{\Delta \mathrm{N}_{2}}{n_{\mathrm{AIR}}} \frac{1}{x_{\mathrm{N}_{2}}}$

Surface fluxes for oceanic $\mathrm{CO}_{2}$, that lead to the term $\Delta \mathrm{O}$, were taken from the $d p \mathrm{CO}_{2}$-derived data set by Takahashi et al. (2002), with long-term mean fluxes taken from the inversion of ocean interior data by Gloor et al. (2001). Oceanic $\mathrm{O}_{2}, \Delta \mathrm{Z}$ in Eq. (9), is based on the flux climatology by Garcia and Keeling (2001), with long-term fluxes by Gruber et al. (2001). Anthropogenic $\mathrm{CO}_{2}$ estimates $(\Delta F)$ were based on the emissions reported by the Emission Database for Global Atmospheric Research (EDGAR, Olivier and Berdowski, 2001), augmented with diurnal, weekly, and seasonal variations (in addition to the interannual variations), and extrapolated to recent years based on BP statistics (BP, 2008). As APO has been expressed in units of per meg representing the variation from the beginning of the year 2000, adopting the usual constants to convert from number of moles and vice versa, the model has been corrected for the $\mathrm{N}_{2}$ influence present in the measured APO signal due to $\mathrm{N}_{2}$ ingassing and outgassing of the oceans. A term derived from simulations based on $\mathrm{N}_{2}$ fluxes from the OPA/PISCEST ocean biogeochemical model by Le Quéré et al. (2007; and references therein) has been added to Eq. (9).

The simulation runs started in 1995 and ended in 2006, having six-hourly resolution. For each air sample the corresponding model result has been looked up and used, simulated for the same day and time range as the physical air sample. Furthermore, in analogy with the observed data, an arbitrary offset has first been derived for each component, by extrapolating the linear trend through all data at the time 2000 , and then this offset has been removed from the data series of that component. In the plots of Fig. 4, model output is presented as plus-signs and the associated fitting curves are drawn as dashed lines. Panel a refers to Mace Head and panel $\mathrm{b}$ refers to Lutjewad. The parameters characterising the fitting curves are summarized in Table 3; in particular, the trend values refer to the curves in Fig. 4, while the peak-to-trough amplitudes and phases refer to the more accurate evaluation obtained by average detrended data shown in Fig. 6. So, observing both Fig. 4 and Table 3, we can summarise by saying that the model can realistically reproduce the observations at Mace Head, in agreement with other successful comparison between observations taken at Northern hemisphere background stations, such as Alert (Canada) and TM3-based model simulations (Battle et al., 2006).

However, model-observation agreement shows clear deficits for Lutjewad. Being at the same latitude both on the North Atlantic Ocean, Lutjewad and Mace Head were expected to show comparable APO behaviour, as confirmed by the comparable model predictions. However, the observations demonstrate a larger amplitude and a steeper slope at Lutjewad than both the model predictions and the Mace Head observations show.

We already mentioned the fact that the term $(\phi-\beta) \cdot \Delta F$ could be larger than assumed in first instance, due to the differing oxidative ratios of biospheric processes and fossil fuel combustion, producing local trends in the APO that models fail to describe. This term is the residual of the fossil fuel combustion processes that is not accounted for, and thus not removed in what should be an oceanic tracer. We speculate that at Lutjewad a proper account of the local fossil fuel influence would lead to a better representation of the steeper trend than what appears in the comparison between observations and modelled data in Fig. 4 and Table 3. When we investigate the mean difference between observations and simulations as a function of $(\phi-\beta)$, this mean difference is $-3.29 \mu \mathrm{mol} \mathrm{O}_{2} / \mathrm{mol}$ dry air when we put in the usual value of 0.3 for $(\phi-\beta)$. Enlarging $(\phi-\beta)$, as might be realistic for the situation in the Netherlands, the difference gets more positive and in a linear way becomes zero when $(\phi-\beta)$ is equal to 0.64 and thus $\phi$ would be equal to 1.74 . This finding agrees very well with the annual average OR of $1.69 \pm 0.06$ derived from the particular Dutch fuel mix estimate, based on quarterly records of fossil fuel consumption in The Netherlands in the early 1990s, as reported by Meijer et al. (1996) and summarised in the plot of Fig. 5: calculated by assigning an average oxidative ratio of $1.17,1.4$ and 1.95 respectively to each of the three fuel categories, solid, liquid and gas as in Keeling (1988).

The detrended observational data have been merged by month of the year. For Mace Head, given the scarcity of data points they have been merged every two months to make each point more representative of the whole time range. The selected model outputs were detrended and fitted in the same way as the observations. The APO seasonality is thus shown in Fig. 6a (Mace Head) and Fig. 6b (Lutjewad). The first six months' averages have been repeated for a better clarity of the presentation. The harmonic fit peak-to-trough amplitudes and phases are reported in Table 3. Looking at the climatology of both APO records we can notice similar features as well, among which the presence of a second, higher 


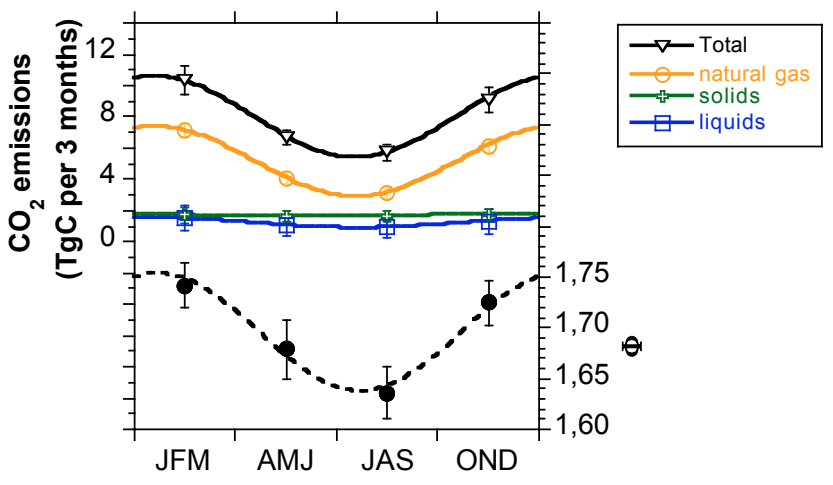

Fig. 5. The seasonality of the Dutch fossil fuel mix and of the resulting fossil fuel oxidative ratio.

relative maximum during the months in early autumn, following the one in early summer, as highlighted by a second curve fit through the Mace Head APO climatology data. This last curve contains also a second harmonic component together with the fundamental one of the seasonal cycle, with the purpose to follow more closely the data. We note that the deviation from the single harmonic fit curve relies on one (two-months mean) value only, agrees within the uncertainties with the neighbouring values as well as with the first fit curve and thus has a very weak statistical base. However, the August (monthly mean) value at Lutjewad also shows a similar lower tendency, whereas the September and October values show up above the sine fit curve. We suggest that the first maximum is mainly an effect of the increase of marine primary production, following the increased availability of light in phase with nutrient availability. The second peak occurs in coincidence with the highest surface temperatures, and therefore could be caused by thermal outgassing in response to the decrease in the gas solubility following the increase in temperature.

Here, we also want to investigate the possible amplification of the fossil fuel emissions' seasonal cycle as an effect of the enhanced $(\phi-\beta)$ difference. Of course the higher this difference the higher would be the influence on APO of any seasonal dynamics in the $\mathrm{CO}_{2}$ emitted by fossil fuel combustion and cement manufacturing. Furthermore, if the values of $\beta$ and $\phi$ themselves are subject to seasonal variations, both introduce another additional seasonal variability to the tracer, again due to the spatial proximity to the anthropogenic contribution. When comparing observations with model runs, this extra variability in the observations would not be captured in the model simulations yet, and might be interpreted as a deficiency of the transport fields instead.

For marine background stations the mixing processes are supposed to have smoothed and diluted the seasonal variations and the fuel mix variations of the fossil fuel emission very close to insignificance, and the difference $(\phi-\beta)$ is then only 0.3 , with $\phi$ being taken as 1.4. However, this assump-

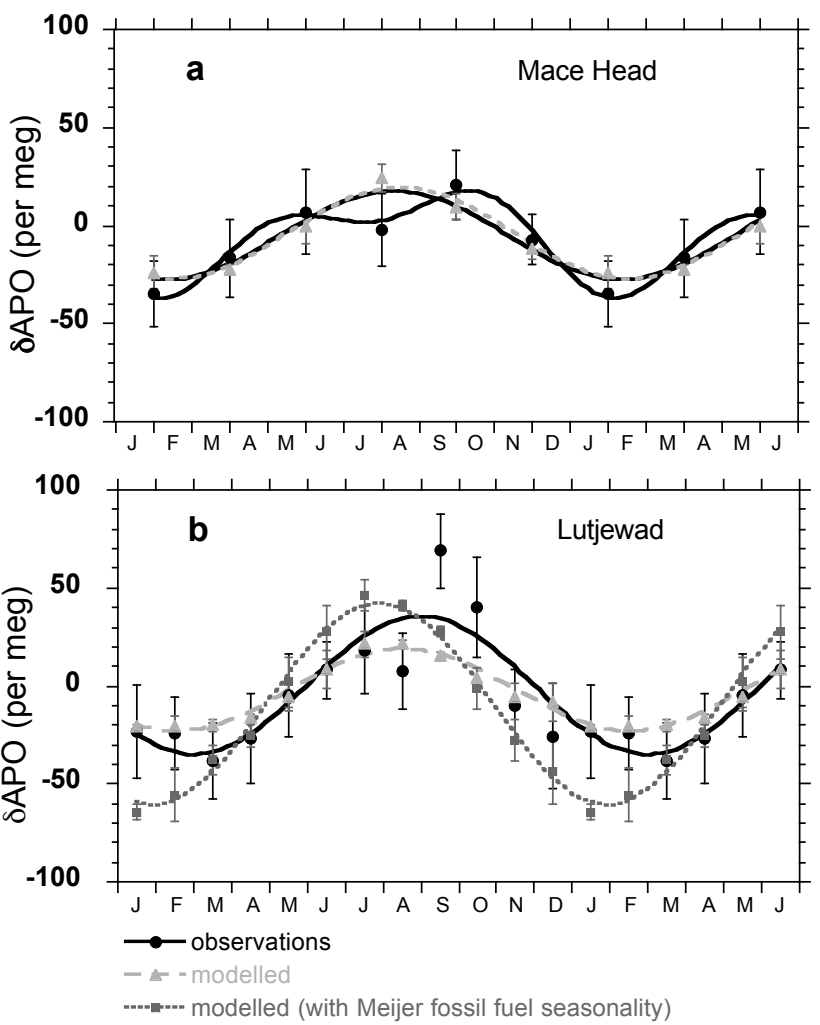

Fig. 6. APO climatology at Mace Head (a) and Lutjewad (b). Monthly (resp. bimonthly for MHD) averages of the detrended APO are represented by black full circles at both stations and compared to model simulations in grey, which at Lutjewad take (squares) or take not (plusses) into account the seasonal variation in the actual fossil fuel mix. The observations (solid lines) and the simulations (dashed lines) are fitted by a single harmonic function. Only for Mace Head a second fitting curve containing also a second harmonic component has been plotted, to highlight the peak occurring during the months September and October at both stations, which does not appear in the model simulations.

tion does not apply when dealing with continental or continentally influenced records. The anthropogenic $\mathrm{CO}_{2}$ sources are too close to be able to assume an efficient dilution of their signals or even a smoothing of their annual variability. Furthermore, $\phi$ can be different from the global mean of 1.4 under local conditions and, for example, in regions with a high natural gas (i.e. methane) share of the fossil fuel mix, it can get closer to two, enhancing the influence of any variation of anthropogenic $\mathrm{CO}_{2}$ emissions on APO. Finally, due to increased use of fertilizer in the agriculture since industrialization, the oxidative ratio $\beta$ has been proposed to become smaller than 1.1 (Ciais et al., 2007). All these factors not only add an extra, not accounted for, negative trend to the APO series that does not belong to any oceanic process, but they augment the difference $(\phi-\beta)$ and amplify the residual signal of fossil fuel combustion. 
Lutjewad station receives air coming directly from the continent, with a higher - and presumably not yet well-mixed - fossil fuel $\mathrm{CO}_{2}$ load. In most of the countries of Western Europe, and most strongly pronounced in the Netherlands, natural gas plays a dominant role, causing $\phi$ to be higher than 1.4 and consequently causing $(\phi-\beta)$ to be higher than the assumed 0.3. Furthermore, as natural gas is mainly used for energy purposes, among them house heating and electricity production, they are subject to variable seasonal demands, that cause a larger uptake of $\mathrm{O}_{2}$ from the atmosphere in winter than in summer in N.W. Europe. Therefore not only the total fossil fuel usage, but also the oxidative ratio associated to it is influenced by seasonal variations, as the demands of all other kinds of fuel stay more or less the same throughout the whole year. This process occurs in phase with the oceanic $\mathrm{O}_{2}$ uptake; therefore the APO amplitude experiences a deepening of the winter trough, hence an increase of the amplitude. Here the variation during one typical year of fuel consumption is shown, bunched in the three main categories solid, liquid and gas (see Fig. 5). Comparing the model curves, especially at Lutjewad, shows that the seasonal variation in the fossil fuel emission is important even when evaluating APO, which should be strictly representative of marine processes alone. Kozlova et al. (2008) have also experienced a bad agreement in their APO model simulation vs. observations comparison exercise. Therefore they already pointed to the question on how strong the influence of the chosen oxidative ratio on this comparability can be.

Assuming that the fossil fuel component of the APO tracer has the variability of its source, we started using estimates of the fossil fuel contents which do not account for seasonal or diurnal variation (i.e. simply based on annual EDGAR statistics) and we have modulated them according to the curve of the total quarterly $\mathrm{C}$ emissions. Furthermore, we have tuned also the factor $\phi$ in that equation according to the OR curve representing its annual Dutch behaviour, taking 1.69 as the average value. In this way, we obtain an extreme estimate of a seasonally variable strength of the fossil fuel term, $F$ in Eq. (6), that we define as model-modified output. This representation of the fossil fuel component stands for a higher limit to its variability, however, it is hard to believe that this kind of signal can get more variable than when it was produced at the source; transport is always expected to dilute and smooth it.

The last row in Table 3, which gives the parameters of the fitting curves through these estimates, confirms that we could reproduce the trend measured at Lutjewad by considering the particular Dutch fuel mix, but we keep missing the amplitude by overestimating the variability of the tracer. We definitely cannot catch the phase of the signal measured at Lutjewad. The larger amplitude could be the result of smaller rectifying effects above this area than at Mace Head, that the model fails to reproduce.

It is, however, more likely that both these features, the steeper trend and the high amplitude, are caused by the fact that the fossil fuel influence on Lutjewad record is different from what is assumed in Eq. (6), and the model fails to reproduce properly its seasonal variability.

This example demonstrates the non-trivial effect of the terrestrial anthropogenic component on APO. Of course, the effect becomes larger the closer we get to the continents and to the anthropogenic sources. The effect could be accounted for by using a new tracer $\mathrm{APO}^{*}$ defined as follows:

$$
\begin{aligned}
& \Delta \delta \mathrm{APO}^{*} \\
& =\delta\left(\mathrm{O}_{2} / \mathrm{N}_{2}\right)+\frac{1}{x_{\mathrm{O}_{2}}} \cdot\left[\beta-f^{*}\left(\phi^{*}-\beta\right)\right] \cdot\left(\mathrm{ppmCO}_{2}-350\right)
\end{aligned}
$$

Here $f^{*}$ is the fraction of the atmospheric $\mathrm{CO}_{2}$ concentration originating from industrial processes and $\phi^{*}$ the OR for fossil fuel and cement production processes characteristic of a given region. The factor $f^{*}$ could be determined e.g. by radiocarbon analysis or by $\mathrm{CO}$ concentration measurements as a proxy (e.g. Meijer et al., 1996; Gamnitzer et al., 2006; Levin and Karstens, 2007; Levin et al., 2008), keeping in mind that $f^{*}$ and $\phi^{*}$ (thus also $\phi^{*}-\beta$ ) have a spatial as well as a seasonal variability.

According to its definition APO* represents a fully observation-based tracer isolating an oceanic signal.

\section{Conclusions}

The analysis of this data set gives new insights into the $\mathrm{CO}_{2}$ exchange processes occurring regionally in Europe, by showing seasonal variations over 5 years, in both the atmospheric $\mathrm{O}_{2} / \mathrm{N}_{2}$ ratios and $\mathrm{CO}_{2}$ concentrations as measured from the costal stations of Lutjewad and Mace Head. In the period from mid-2001 until mid-2005, we see an average increase of $\mathrm{CO}_{2}$ in the atmosphere of $(1.7 \pm 0.2) \mathrm{ppm} \mathrm{y}^{-1}$, and a corresponding decrease of the airborne $\mathrm{O}_{2}$ fraction of $(-20 \pm 2)$ per meg $\mathrm{y}^{-1}$, mainly caused by human activities, particularly fossil fuel burning. The major feature in the records is the fast decrease of the airborne $\mathrm{O}_{2}$. This decrease must be caused by an $\mathrm{O}_{2}$ sink up to now not accounted for. Two mechanisms have recently been proposed in the literature (Ciais et al., 2007; Randerson et al., 2006). An $\mathrm{O}_{2}$ decrease acceleration seems to have started during or shortly after the anomalously hot and dry summer in Europe of 2003. A relation between both is, however, still speculative, and the statistical base and significance are still small.

A climatology of the two species has also been derived. The seasonal cycles are influenced by the location of the two sampling sites more than the inter-annual long trends, with dampened amplitudes registered at Mace Head as effect of the marine character of this sampling station. Here the difference between the $\mathrm{CO}_{2}$ summer trough and the winter peak is $(14.4 \pm 0.3) \mathrm{ppm}$, while the paraphase variation in the $\mathrm{O}_{2}$ signal equals $(113 \pm 3)$ per meg. Almost half of the latter variation is due to marine processes as indicated by the 
APO climatology, derived for this station. At Lutjewad the $\mathrm{CO}_{2}$ and $\mathrm{O}_{2}$ peak-to-peak amplitudes are $(16.1 \pm 0.4) \mathrm{ppm}$ and (153 \pm 3$)$ per meg, respectively.

From the analysis of the Lutjewad time series, we learned that the seasonal variation of APO can be strongly influenced by processes different from those related to marine fluxes alone. A component of this APO seasonality, in an attenuated way also present in the Mace Head record, is caused by the seasonality of fossil fuel consumption and the associated mean oxidative ratio. This component needs to be taken into account in the model simulations as could be shown here by the largely improved agreement between the measurements and the model data when applying the OR of the actual regional fossil fuel mix. Therefore, more data on the anthropogenic emission fields are needed, both spatially and temporarily resolved. Alternatively, we propose to find another tracer capable to test models simulating transport of oceanic components over the continents. We suggest to examine a tracer APO*, similar to APO, but including a correction for all fossil fuel contributions as well. Extra input, in the form of fossil fuel $\mathrm{CO}_{2}$ measurements, is therefore needed. Radiocarbon measurements, eventually supplemented by $\mathrm{CO}$ concentration measurements with high timeresolution, could help to detect the fossil fuel fraction of the airborne $\mathrm{CO}_{2}$. This kind of observations is often associated to $\mathrm{CO}_{2}$ and $\mathrm{O}_{2}$ records (for example in the CarboEurope IP network, cf. www.carboeurope.org) and they could, therefore, help to remove the residual anthropogenic component from the APO derivation.

Acknowledgements. This work has been supported in the framework of the EU-funded projects AEROCARB and CarboEurope-IP. We thank Gerry Spain for taking care of the sampling operations at the Atmospheric Research Station Mace Head. We acknowledge the always enthusiastic cooperation, received from Bert Kers, concerning all technical aspects, both at Lutjewad station and in the laboratory. Finally, we want to thank Piet Weber for his help with the gas chromatograph for the flask $\mathrm{CO}_{2}$ concentration measurements, during the start-up phase of this study.

We gratefully acknowledge the remarks, questions and suggestions received from three reviewers and one commentator, with special thanks to A. C. Manning, who all helped to greatly improve the article.

Edited by: R. Ebinghaus

\section{References}

Bacastow, R., Keeling, C. D., and Whorf, T.: Seasonal Amplitude Increase in Atmospheric $\mathrm{CO}_{2}$ Concentration at Mauna Loa, Hawaii, 1959-1982, J. Geophys. Res., 90, 10529-10540, 1985.

Balkanski, Y., Monfray, P., Battle, M., and Heimann, M.: Ocean primary production derived from satellite data: An evaluation with atmospheric oxygen measurements, Global Biogeochem. Cy., 13, 257-271, 1999.
Battle, M., Bender, M. L., Tans, P. P., White, J. W. C., Ellis, J. T., Conway, T., and Francey, R. J.: Global carbon sinks and their variability inferred from atmospheric $\mathrm{O}_{2}$ and $\delta^{13} \mathrm{C}$, Science, 287, 2467-2470, 2000.

Battle, M., Fletcher, S. M., Bender, M. L., Keeling, R. F., Manning, A. C., Gruber, N., Tans, P. P., Hendricks, M. B., Ho, D. T., Simonds, C., Mika, R., and Paplawsky, B.: Atmospheric Potential Oxygen: New observations and their implications for some atmospheric and oceanic models, Global Biogeochem. Cy., 20, GB1010, doi:10.1029/2005GB002534, 2006.

Bender, M., Ellis, T., Tans, P., Francey, R., and Lowe, D.: Variability in the $\mathrm{O}_{2} / \mathrm{N}_{2}$ ratio of southern hemisphere air, 1991-1994: Implications for the Carbon cycle, Global Biogeochem. Cy., 10, 9-21, 1996.

Bender, M. L., Tans, P. P., Ellis, J. T., Orchardo, J., and Habfast, $\mathrm{K}$.: A high-precision isotope ratio mass spectrometry method for measuring the $\mathrm{O}_{2} / \mathrm{N}_{2}$ ratio of air, Geochim. Cosmochim. Ac., 58, 4751-4758, 1994.

Boden, T. A., Marland, G., and Andres, R. J.: Global, Regional, and National Fossil-Fuel $\mathrm{CO}_{2}$ Emissions. Carbon Dioxide Information Analysis Center, Oak Ridge National Laboratory, US Department of Energy, Oak Ridge, Tenn., USA, doi:10.3334/CDIAC/00001, available online at: http://cdiac.ornl. gov/trends/emis/overview_2006.html, last access: 12 January 2010, 2009.

Bousquet, P., Gaudry, A., Ciais, P., Kazan, V., Monfray, P., Simmonds, P. G., Jennings, S. G., and O'Connor, T. C.: Atmospheric $\mathrm{CO}_{2}$ concentration variations recorded at Mace Head, Ireland from 1992 to 1994, Phys. Chem. Earth, 21, 477-481, 1996.

BP Statistical Review of World Energy June 2008, BP p.l.c., London, UK, also available from www.bp.com/statisticalreview, 2008.

Ciais, P., Tans, P. P., White, J. W. C., Trolier, M., Francey, R. J., Berry, J. A., Randall, D. R., Sellers, P. J., Collatz, J. G., and Schimel, D. S.: Partitioning of ocean and land uptake of $\mathrm{CO}_{2}$ as inferred by $\delta^{13} \mathrm{C}$ measurements from the NOAA Climate Monitoring and Diagnostics Laboratory Global Air Sampling Network, J. Geophys. Res., 100, 5051-5070, 1995.

Ciais, P., Reichstein, M., Viovy, N., Granier, A., Ogée, J., Allard, V., Aubinet, M., Buchmann, N., Bernhofer, C., Carrara, A., Chevallier, F., De Noblet, N., Friend, A. D., Friedlingstein, P., Grünwald, T., Heinesch, B., Keronen, P., Knohl, A., Krinner, G., Loustau, D., Manca, G., Matteucci, G., Miglietta, F., Ourcival, J. M., Papale, D., Pilegaard, K., Rambal, S., Seufert, G., Soussana, J. F., Sanz, M. J., Schulze, E. D., Vesala, T., and Valentini, R.: Europe-wide reduction in primary productivity caused by the heat and drought in 2003, Nature, 437, 529-533, 2005.

Ciais, P., Manning, A. C., Reichstein, M., Zaehle, S., and Bopp, L.: Nitrification amplifies the decreasing trends of atmospheric oxygen and implies a larger land carbon uptake, Global Biogeochem. Cy., 21, GB2030, doi:10.1029/2006GB002799, 2007.

Cleveland, R. B., Cleveland, W. S., McRae, J. E., and Terpenning, I.: STL: A seasonal-trend decomposition procedure based on Loess, J. Off. Stat., 6, 3-73, 1990.

Denning, A. S., Takahashi, T., and Friedlingstein, P.: Keynote perspective. Can a strong atmospheric $\mathrm{CO}_{2}$ rectifier effect be reconciled with a "reasonable" Carbon budget?, Tellus B, 51, 249-253, 1999.

Derwent, R. G., Ryall, D. B., Manning, A. J., Simmonds, P. G., 
O'Doherty, S., Biraud, S., Ciais, P., Ramonet, M., and Jennings, S. G.: Continuous observations of carbon dioxide at Mace Head, Ireland from 1995 to 1999 and its net European ecosystem exchange, Atmos. Environ., 36, 2799-2807, 2002.

Gamnitzer, U., Karstens, U., Kromer, B., Neubert, R. E. M., Meijer, H. A. J., Schroeder, H., and Levin, I.: Carbon monoxide: A quantitative tracer for fossil fuel $\mathrm{CO}_{2}$, J. Geophys. Res., 111, D22302, doi:10.1029/2005JD006966, 2006.

Garcia, H. E. and Keeling, R. F.: On the global oxygen anomaly and air-sea flux, J. Geophys. Res. Atmos., 106, 31155-31166, 2001.

Gloor, M., Gruber, N., Hughes, T. M. C., and Sarmiento, J. L.: Estimating net air-sea fluxes from ocean bulk data: Methodology and application to the heat cycle, Global Biogeochem. Cy., 15, 767-782, 2001.

Gruber, N., Gloor, M., Fan, S.-M., and Sarmiento, J. L.: Air-sea flux of oxygen estimated from bulk data: Implications for the marine and atmospheric oxygen cycles, Global Biogeochem. Cy., 15, 783-803, 2001.

IPCC: Climate Change 2007: The Physical Science Basis. Contribution of Working Group I to the Fourth Assessment Report of the Intergovernmental Panel on Climate Change, edited by: Solomon, S., Qin, D., Manning, M., Chen, Z., Marquis, M., Averyt, K. B., Tignor, M., and Miller, H. L., Cambridge University Press, Cambridge, UK and New York, NY, USA, 996 pp., 2007.

Keeling, C. D., Whorf, T. P., Wahlen, M., and van der Plicht, J.: Interannual extremes in the rate of rise of atmospheric carbon dioxide since 1980, Nature, 375, 666-670,1995.

Keeling, R. F., Najjar, R., Bender, M., and Tans, P. P.: What atmospheric oxygen measurements can tell us about the global carbon cycle, Global Biogeochem. Cy., 7, 37-67, 1993.

Keeling, R. F.: Development of an interferometric oxygen analyzer for precise measurement of atmospheric $\mathrm{O}_{2}$ mole fraction, $\mathrm{PhD}$ Thesis, Harvard University, USA, 1988.

Keeling, R. F. and Shertz, S. R.: Seasonal and interannual variations in atmospheric oxygen and implications for the global carbon cycle, Nature, 358, 723-727, 1992.

Keeling, R. F., Piper, S. C., and Heimann, M.: Global and hemispheric $\mathrm{CO}_{2}$ sinks deduced from changes in atmospheric $\mathrm{O}_{2}$ concentration, Nature, 381, 218-221, 1996.

Keeling, R. F., Stephens, B. B., Najjar, R. G., Doney, S. C., Archer, D., and Heimann, M.: Seasonal variations in the atmospheric $\mathrm{O}_{2} / \mathrm{N}_{2}$ ratio in relation to the kinetics of air-sea gas exchange, Global Biogeochem. Cy., 12, 141-163, 1998.

Kozlova, E. A., Manning, A. C., Kisilyakhov, Y., Seifert, T., and Heimann, M.: Seasonal, synoptic, and diurnal-scale variability of biogeochemical trace gases and $\mathrm{O}_{2}$ from a 300-m tall tower in central Siberia, Global Biogeochem. Cy., 22, GB4020, doi:10.1029/2008GB003209, 2008.

Langenfelds, R. L., Francey, R. J., Steele, L. P., Battle, M., Keeling, R. F., and Budd, W. F.: Partitioning of the global fossil $\mathrm{CO}_{2}$ sink using a 19-year trend in atmospheric $\mathrm{O}_{2}$, Geophys. Res. Lett., 26, 1897-1900, 1999.

Le Quéré, C., Aumont, O., Bopp, L., Bousquet, P., Ciais, P., Francey, R., Heimann, M., Keeling, C. D., Keeling, R. F., Kheshgi, H., Peylin, P., Piper, S. C., Prentice, I. C., and Rayner, P. J.: Two decades of ocean $\mathrm{CO}_{2}$ sink and variability, Tellus B, 55, 649-656, 2003.

Le Quéré, C., Rödenbeck, C., Buitenhuis, E. T., Conway, T. J., Langenfelds, R., Gomez, A., Labuschagne, C., Ramonet, M.,
Nakazawa, T., Metzl, N., Gillett, N., and Heimann, M.: Saturation of the Southern Ocean $\mathrm{CO}_{2}$ sink due to recent Climate Change, Science, 316, 5832, doi:10.1126/science.1136188, 2007.

Levin, I., Hammer, S., Kromer, B., and Meinhardt, F.: Radiocarbon observations in atmospheric $\mathrm{CO}_{2}$ : Determining fossil fuel $\mathrm{CO}_{2}$ over Europe using Jungfraujoch observations as background, Sci. Total Environ., 391, 211-216, 2008.

Levin, I. and Karstens, U.: Inferring high-resolution fossil fuel $\mathrm{CO}_{2}$ records at continental sites from combined ${ }^{14} \mathrm{CO}_{2}$ and $\mathrm{CO}$ observations, Tellus B, 59, 245-250, 2007.

Levitus, S., Antonov, J. I., Boyer, T. P., and Stephens, C.: Warming of the world ocean, Science, 287, 2225-2229, 2000.

Manning, A. C.: Temporal variability of atmospheric oxygen from both continuous measurements and a flask sampling network: Tools for studying the global carbon cycle, $\mathrm{PhD}$ Thesis, University of California, San Diego, USA, 202 pp., 2001.

Manning, A. C., Keeling, R. F., Katz, L. E., Paplawsky, W. J., and McEvoy, E. M.: Interpreting the seasonal cycles of atmospheric oxygen and carbon dioxide concentrations at American Samoa Observatory, Geophys. Res. Lett., 30, 1333, doi:10.1029/2001GL014312, 2003.

Manning, A. C. and Keeling, R. F.: Global oceanic and land biotic carbon sinks from the Scripps atmospheric oxygen flask sampling network, Tellus B, 58, 95-116, 2006.

Meijer, H. A. J., Smid, H. M., Perez, E., and Keizer, M. G.: Isotopic characterisation of anthropogenic $\mathrm{CO}_{2}$ emissions using isotopic and radiocarbon analysis, Phys. Chem. Earth, 21, 483-487, 1996.

Miller, J. (ed.): Report of the thirteenth WMO/IAEA meeting of experts on Carbon Dioxide concentration and related tracer measurement techniques, Boulder, Colorado, USA, 19-22 September 2005, WMO-GAW No.168, Geneve, Switzerland, 2005.

Nakazawa, T., Ishizawa, M., Higuchi, K., and Trivett, N. B. A.: Two curve fitting methods applied to $\mathrm{CO}_{2}$ flask data, Environmetrics, 8, 197-218, 1997.

Neubert, R. E. M., Spijkervet, L. L., Schut, J. K., Been, H. A., and Meijer, H. A. J.: A computer-controlled continuous air drying and flask sampling system, J. Atmos. Ocean. Tech., 21, 651-659, 2004.

Neubert, R. E. M., Weber, P., Gerritsma, R., and Meijer, H. A. J.: The Atmospheric $\mathrm{CO}_{2}$ and greenhouse gas monitoring activities at Lutjewad, The Netherlands, in: Report of the twelfth WMO/IAEA meeting of experts on Carbon Dioxide concentration and related tracer measurement techniques, Toronto, Canada, 15-18/9/2003, edited by: Worthy, D. and Huang, L., WMO-TD No. 1275, WMO-GAW No.161, Geneve, Switzerland, 203-209, 2005.

Olivier, J. G. J. and Berdowski, J. J. M.: Global emission sources and sinks, in: The climate system, edited by: Berdowski, J., Guicherit, R., and Heij, B. J., A. A. Balkema Publishers/Swets \& Zeitlinger Publishers, Lisse, The Netherlands, 33-78, 2001.

Prentice, I. C., Farquhar, G. D., Fasham, M. J. R., Goulden, M. L., Heimann, M., Jaramillo, V. J., Kheshgi, H. S., LeQuéré, C., Scholes, R. J., and Wallace, D. W. R.: The Carbon Cycle and Atmospheric Carbon Dioxide, in Climate Change 2001: The Scientific Basis, edited by: Houghton, J. T., Ding, Y., Griggs, D. J., et al., Cambridge University Press: Cambridge, 2001.

Press, W. H., Flannery, B. P., Teukolsky, S. A., and Vetterling, W. T.: General linear least squares fit, in: Numerical recipes in C: The 
art of scientific computing, Cambridge University Press, Cambridge, UK, 671-681, 1992.

Ramonet, M., Ciais, P., Aalto, T., Aulagnier, C., and co-authors: A recent build-up of atmospheric $\mathrm{CO}_{2}$ over Europe. Part 1: Observed signals and possible explanations. Tellus 62B, 1-13, doi:10.1111/j.1600-0889.2009.00442.x, 2010.

Randerson, J. T., Masiello, C. A., Still, C. J., Rahn, T., Poorter, H., and Field, C. B.: Is carbon within the global terrestrial biosphere becoming more oxidized? Implications for trends in atmospheric $\mathrm{O}_{2}$, Global Change Biol., 12, 260-271, 2006.

Raupach, M. R., Marland, G., Ciais, P., Le Quéré, C., Canadell, J. G., Klepper, G., and Field, C. B.: Global and regional drivers of accelerating $\mathrm{CO}_{2}$, emissions, Proc. Natl. Acad. Sci. USA, 104, doi:10.1073/pnas.0700609104, 10288-10293, 2007.

Rayner, P. J., Enting, I. G., Francey, R. J., and Langenfelds, R. L.: Reconstructing the recent carbon cycle from atmospheric $\mathrm{CO}_{2}$, $\delta^{13} \mathrm{C}$ and $\mathrm{O}_{2} / \mathrm{N}_{2}$ observations, Tellus B, 51, 213-232, 1999.

Rödenbeck, C.: Estimating $\mathrm{CO}_{2}$ sources and sinks from atmospheric mixing ratio measurements using a global inversion of atmospheric transport, Max-Planck-Institute for Biogeochemistry, Technical Reports Nr. 6, Jena, Germany, ISSN 1615-7400, 53 pp., 2005.

Severinghaus, J. P.: Studies of the terrestrial $\mathrm{O}_{2}$ and Carbon Cycles in sand dune gases and in Biosphere 2, PhD Thesis, Columbia University, New York, USA, 148 pp., 1995.

Stephens, B. B., Keeling, R. F., Heimann, M., Six, K. D., Murnane, R., and Caldeira, K.: Testing global ocean carbon models using measurements of atmospheric $\mathrm{O}_{2}$ and $\mathrm{CO}_{2}$ concentration, Global Biogeochem. Cy., 12, 213-230, 1998.

Stephens, B. B.: Field-based atmospheric oxygen measurements and the ocean carbon cycle, $\mathrm{PhD}$ Thesis, University of California, San Diego, USA, 221 pp., 1999.

Stephens, B. B., Bakwin, P. S., Tans, P. P., Teclaw, R. M., and Baumann, D. D.: Application of a differential fuel-cell analyzer for measuring atmospheric oxygen variations, J. Atmos. Ocean. Tech., 24, 82-94, 2007.

Sturm, P., Leuenberger, M., Sirignano, C., Neubert, R. E. M., Meijer, H. A. J., Langenfelds, R. L., Brand, W. A., and Tohjima, Y.: Permeation of atmospheric gases through polymer O-rings used in flasks for air sampling, J. Geophys. Res., 109, D04309, doi:10.1029/2003JD004073, 2004.

Sturm, P., Leuenberger, M., Moncrieff, J., and Ramonet, M.: Atmospheric $\mathrm{O}_{2}, \mathrm{CO}_{2}$ and $\delta^{13} \mathrm{C}$ measurements from aircraft sampling over Griffin Forest, Perthshire, UK, Rapid Commun. Mass Sp., 19, 2399-2406, 2005a.

Sturm, P., Leuenberger, M., and Schmidt, M.: Atmospheric $\mathrm{O}_{2}$, $\mathrm{CO}_{2}$ and $\delta^{13} \mathrm{C}$ observations from the remote sites Jungfraujoch, Switzerland, and Puy de Dôme, France, Geophys. Res. Lett., 32, L17811, doi:10.1029/2005GL023304, 2005b.
Sturm, P., Leuenberger, M., Valentino, F. L., Lehmann, B., and Ihly, B.: Measurements of $\mathrm{CO}_{2}$, its stable isotopes, $\mathrm{O}_{2} / \mathrm{N}_{2}$, and ${ }^{222} \mathrm{Rn}$ at Bern, Switzerland, Atmos. Chem. Phys., 6, 1991-2004, 2006, http://www.atmos-chem-phys.net/6/1991/2006/.

Takahashi, T., Sutherland, S.C., Sweeney, C., Poisson, A., Metzl, N., Tilbrook, B., Bates, N., Wanninkhof, R., Feely, R. A., and Sabine, C.: Global sea-air $\mathrm{CO}_{2}$ flux based on climatological surface ocean $\mathrm{pCO}_{2}$, and seasonal biological and temperature effects, Deep Sea Res. Pt. II, 49, 1601-1622, 2002.

Tans, P. P., Conway, T. J., and Nakazawa, T.: Latitudinal distribution of the sources and sinks of atmospheric carbon dioxide derived from surface observations and an atmospheric transport model, J. Geophys. Res., 92, 5151-5172, 1989.

Tans, P. P., Fung, I. Y., and Takahashi, T.: Observational constraints on the global atmospheric $\mathrm{CO}_{2}$ budget, Science, 247, 14311438, 1990.

Tohjima, Y., Mukai, H., Nojiri, Y., Yamagishi, H., and Machida, T.: Atmospheric $\mathrm{O}_{2} / \mathrm{N}_{2}$ measurements at two Japanese sites: estimation of global oceanic and land biotic carbon sinks and analysis of the variations in atmospheric potential oxygen (APO), Tellus, 60B, 213-225, 2008.

Valentino, F. L., Leuenberger, M., Uglietti, C., and Sturm, P.: Measurements and trend analysis of $\mathrm{O}_{2}, \mathrm{CO}_{2}$ and $\delta^{13} \mathrm{C}$ of $\mathrm{CO}_{2}$ from the high altitude research station Junfgraujoch, Switzerland - A comparison with the observations from the remote site Puy de Dôme, France, Sci. Total Environ., 391, 203-210, 2008.

Van der Laan, S., Neubert. R. E. M., and Meijer, H. A. J.: A single gas chromatograph for accurate atmospheric mixing ratio measurements of $\mathrm{CO}_{2}, \mathrm{CH}_{4}, \mathrm{~N}_{2} \mathrm{O}, \mathrm{SF}_{6}$ and $\mathrm{CO}$, Atmos. Meas. Tech., 2, 549-559, 2009a,

http://www.atmos-meas-tech.net/2/549/2009/.

Van der Laan, S., Neubert, R. E. M. and Meijer, H. A. J.: Methane and nitrous oxide emissions in the Netherlands: ambient measurements support the national inventories, Atmos. Chem. Phys., 9, 9369-9379, 2009b, http://www.atmos-chem-phys.net/9/9369/2009/.

Worthy, D. E. J. and Huang, L. (eds): Report of the twelfth WMO/IAEA meeting of experts on Carbon Dioxide concentration and related tracer measurement techniques, Toronto, Canada, 15-18/9/2003, WMO-TD No. 1275, WMO-GAW No.161, 203-209, Geneve, Switzerland, 2005.

Worthy, D. E. J., Platt, A., Kessler, R., Ernst, M., and Racki, S.: The Greenhouse Gases Measurement Program: Measurement procedures and data quality, in: Canadian Baseline Program: Summary of Progress to 2002, edited by: Worthy, D. E. J., Environment Canada, Downsview, Ontario, Canada, 2003.

Zhao, C. L. and Tans, P. P.: Estimating uncertainty of the WMO mole fraction scale for carbon dioxide in air, J. Geophys. Res., 111, D08S09, doi:10.1029/2005JD006003, 2006. 